\title{
Executive control of gaze by the frontal lobes
}

\author{
JefFrey D. SChall ANd Leanne Boucher \\ Vanderbilt University, Nashville, Tennessee
}

\begin{abstract}
Executive control requires controlling the initiation of movements, judging the consequences of actions, and adjusting performance accordingly. We have investigated the role of different areas in the frontal lobe in executive control expressed by macaque monkeys performing a saccade stop signal task. Certain neurons in the frontal eye field respond to visual stimuli, and others control the production of saccadic eye movements. Neurons in the supplementary eye field do not control directly the initiation of saccades but, instead, signal the production of errors, the anticipation and delivery of reinforcement, and the presence of response conflict. Neurons in the anterior cingulate cortex signal the production of errors and the anticipation and delivery of reinforcement, but not the presence of response conflict. Intracranial local field potentials in the anterior cingulate cortex of monkeys indicate that these medial frontal signals can contribute to event-related potentials related to performance monitoring. Electrical stimulation of the supplementary eye field improves performance in the task by elevating saccade latency. An interactive race model shows how interacting units produce behavior that can be described as the outcome of a race between independent processes and how conflict between gaze-holding and gaze-shifting neurons can be used to adjust performance.
\end{abstract}

Current hypotheses about the mechanisms of executive control have been developed largely in the domain of human subjects performing tasks involving response interference (such as Stroop or flanker tasks) or reinforcement learning. Distinguishing between alternative hypotheses about executive control has hinged on articulating the relationship (or lack thereof) between monitoring errors, reinforcement feedback, and response conflict. We will review research on the neurophysiological mechanisms observed in macaque monkeys performing a countermanding (stop signal) task with saccadic eye movements. Key insights include elucidation of how the brain controls whether and when a movement will be initiated, demonstration of the coexistence of error, reinforcement, and conflict signals in the medial frontal lobe, and demonstration of a mechanism by which the medial frontal lobe can influence motor structures to adapt performance. These insights grew out of a synthesis of conceptual frameworks and a coordination of neurophysiological, psychophysical, and mathematical modeling techniques.

\section{The Stop Signal Task}

To investigate the neural control of movement initiation and suppression, we have employed the countermanding paradigm with behaving monkeys. Developed to investigate human performance, the countermanding paradigm probes a subject's ability to control the initiation of movements by infrequently presenting an imperative stop signal in a response time task (reviewed by Logan, 1994). The subject's task is to cancel the planned movement if a stop signal is presented. In the ocular motor version, mon- keys were trained to make a saccade to a peripheral target that appeared when the fixation spot disappeared, unless a stop signal was presented (Figure 1). In response to the stop signal, the monkeys were to withhold the movement; the stop signal was the reappearance of the fixation spot (Hanes \& Schall, 1995). Logan and Cowan (1984) showed that performance on this task can be accounted for by a race between a process that generates the movement ( $g o$ process) and a process that cancels the movement (stop process). This race model provides an estimate of the stop signal reaction time, which is the time needed to cancel the planned movement. Stop signal reaction times measured in this saccade countermanding task average around $100 \mathrm{msec}$ in monkeys and around $130 \mathrm{msec}$ in humans (e.g., Hanes \& Carpenter, 1999; Hanes \& Schall, 1995).

Both humans and monkeys learn how to perform the countermanding task relatively quickly, but adjustments of performance continue after the task has been well learned. Any random sample of consecutive trials will vary in the proportion of stop signal trials; sometimes there are more, and sometimes there are few. Subjects have no a priori guarantee of stationarity in the environment, so they adjust speed versus accuracy on an ongoing basis. For example, if many stop signal trials occur, it is adaptive to increase response time, waiting for the stop signal at the cost of delaying reinforcement.

We investigated the nature of these control adjustments in humans and monkeys (Emeric et al., 2007). Despite idiosyncrasies across subjects, several trends were evident (Figure 2). First, as is characteristic for stop signal task performance, the response times on error, noncanceled

J. D. Schall, jeffrey.d.schall@vanderbilt.edu 


\section{No-Stop-Signal Trial}

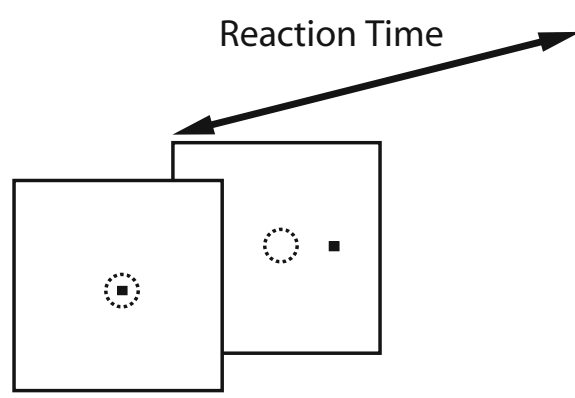

\section{Stop Signal Trial}

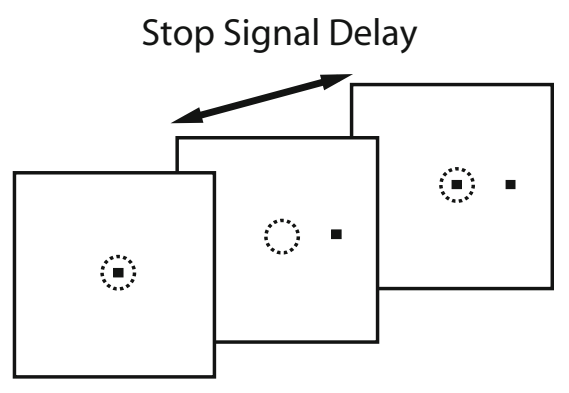

Canceled

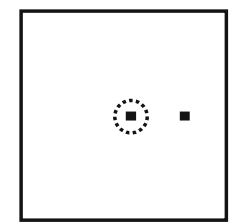

Noncanceled

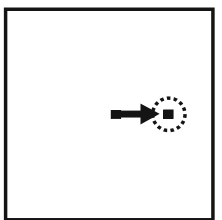

Figure 1. Trial displays for the countermanding task. The dotted circle indicates the focus of gaze at each interval, and the arrow indicates the saccade. All trials began with the presentation of a central fixation spot. After fixation of this spot for a variable interval, it disappeared. Simultaneously, a target appeared at an eccentric location. On a fraction of trials, after a delay, referred to as the stop signal delay, the fixation spot reappeared, instructing the monkey to withhold movement initiation (stop signal trials). During the trials on which the stop signal was not presented (nostop-signal trials), the monkeys were rewarded for generating a single saccade to the peripheral target. During stop signal trials, the monkeys were rewarded for maintaining fixation on the central spot for $\mathbf{7 0 0} \mathbf{m s e c}$ (canceled trials). If the monkeys did generate a saccade to the peripheral target during stop signal trials, no reward was given (noncanceled trials).

(also known as signal-respond) trials were systematically shorter than the response times on trials with no stop signal. This observation is one of the main motivations of the race model. Second, the response time on a no-stop-signal trial tended to decrease with the number of preceding nostop-signal trials. In other words, if more no-stop-signal trials were experienced, subjects sped up. Third, the response time of a no-stop-signal trial tended to increase with the number of preceding stop signal trials. In other words, if more stop signals were experienced, subjects slowed down. Fourth, response time was influenced by performance on the preceding trial. In particular, response times were delayed following correct, canceled (also known as signal-inhibit) trials (see also Rieger \& Gauggel, 1999; Verbruggen, Liefooghe, \& Vandierendonck, 2005). In contrast, response times were delayed less, if at all, following error noncanceled stop trials. These results indicate that the response to a given stimulus depends on

the context derived from the history of previous trials. The original behavioral evidence for a supervisory control system emphasized adjustments in response time following errors in choice response time tasks (e.g., Rabbitt, 1966). Performance of the stop signal task reveals clear strategic adjustments; however, posterror slowing is less pronounced than postinhibition slowing. An explanation for this difference will be considered below.

\section{Eye Fields in the Frontal Cortex}

Before describing our experimental data, we will provide some background on the cortical areas in macaque monkeys, from which the data were collected (Figure 3). We should note, though, that homologues of these areas have been identified in humans, so we believe that the neural processes described in monkeys occur as well in humans.

The frontal eye field (FEF) is an area in the dorsolateral prefrontal cortex, located in the rostral bank of the arcuate sulcus in macaque monkeys. Broadly considered, this cor-
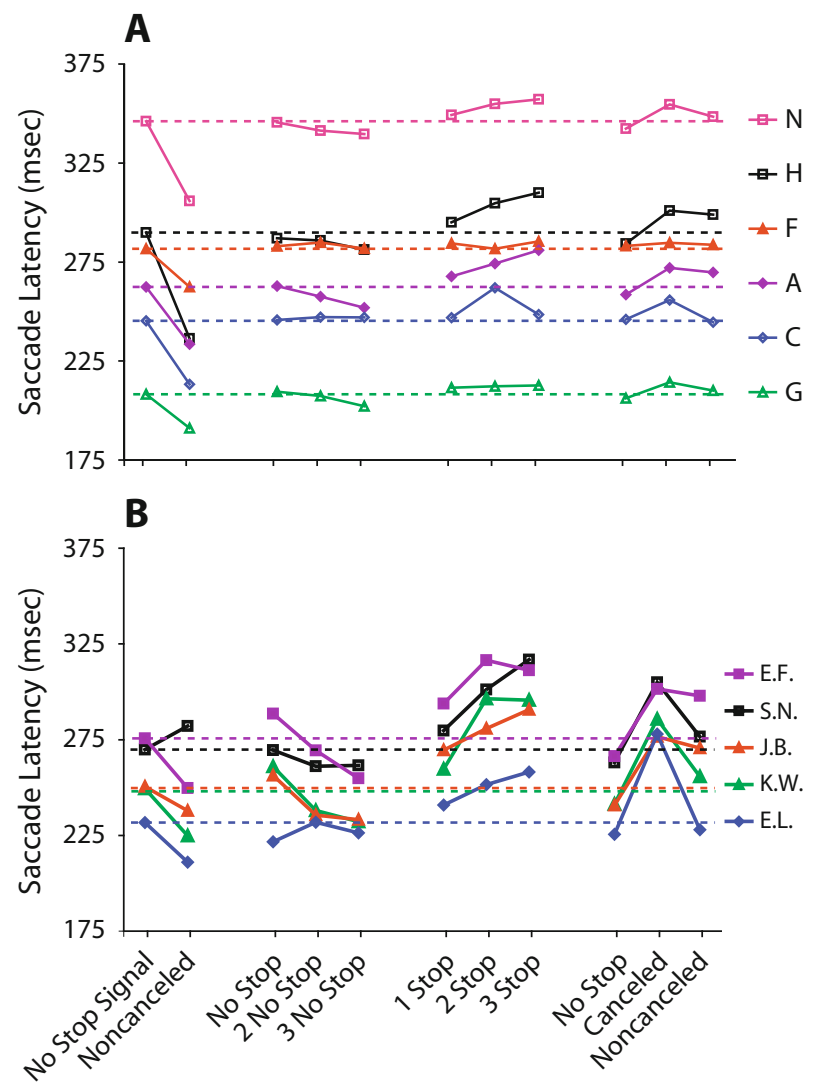

Figure 2. The influence of recent trial history on response time on no-stop-signal trials for monkeys (A) and humans (B). The first columns represent the mean no-stop-signal response time and the mean noncanceled response time. All other columns represent the mean no-stop-signal reaction time for trials, with the sequences of preceding trials indicated on the abscissa. The mean no-stop-signal reaction time for each subject is represented by the horizontal dotted line. From "Influence of History on Countermanding Performance in Humans and Macaque Monkeys," by E. E. Emeric, J. W. Brown, L. Boucher, R. H. S. Carpenter, D. P. Hanes, R. Harris, et al., 2007, Vision Research, 47, p. 39. Copyright 2007 by Elsevier. Adapted with permission. 


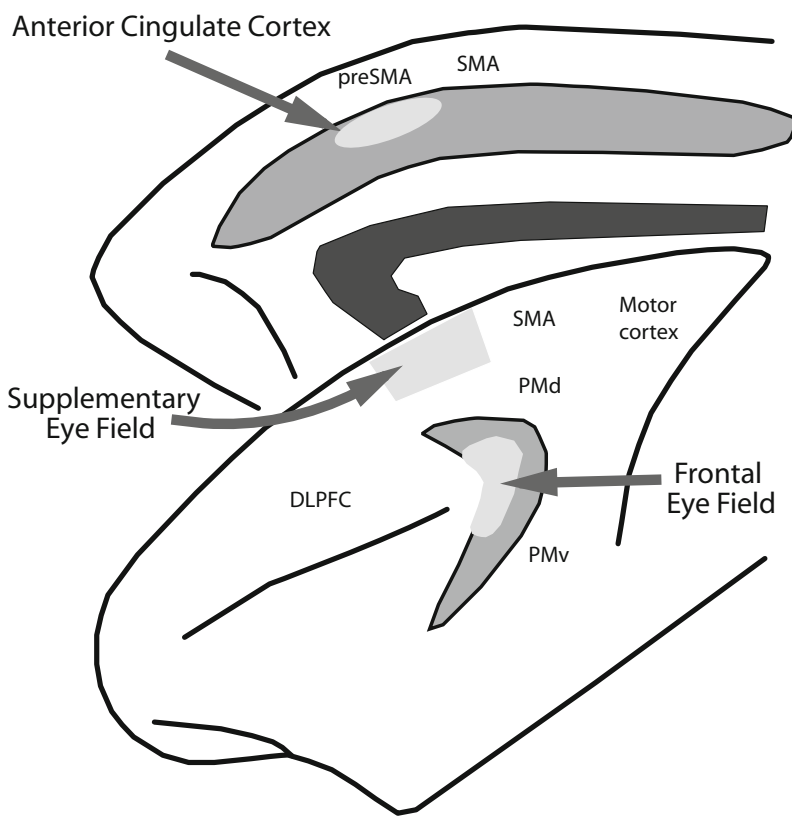

Figure 3. Dorsolateral (lower) and mesial (upper) views of the macaque frontal cortex showing the location of the frontal eye field, the supplementary eye field, and the region of anterior cingulate cortex described in this review. For reference, the general location is shown of the primary motor cortex, supplementary motor area (SMA), presupplementary motor area (preSMA), dorsal premotor cortex (PMd), ventral premotor cortex (PMv), and dorsolateral prefrontal cortex (DLPFC). Light gray highlights opened sulci.

tical area participates in the transformation of visual signals into saccade motor commands (reviewed by Schall, 1997). Physiological recordings in the FEF of monkeys trained to shift gaze to visual targets have shown that roughly half of the neurons have visual responses (e.g., Bruce \& Goldberg, 1985; Schall, 1991a). Recent research has demonstrated how these visually responsive neurons in the FEF participate in the selection of visual targets for saccades (reviewed by Schall \& Thompson, 1999).

The FEF is also known to play a direct role in producing saccadic eye movements. Low-intensity microstimulation of the FEF elicits saccades (e.g., Bruce, Goldberg, Bushnell, \& Stanton, 1985). This direct influence is mediated by a subpopulation of neurons in the FEF that discharge specifically before and during saccades (Bruce \& Goldberg, 1985; Hanes \& Schall, 1996; Schall, 1991a) (Figures 4 and $5 \mathrm{~A}$ ). These neurons that generate movement-related activity innervate the superior colliculus (SC; Segraves \& Goldberg, 1987; Sommer \& Wurtz, 2000) and the neural circuit in the brainstem that generates saccades (Segraves, 1992). Another population of neurons in the FEF and SC are active during fixation and exhibit decreased discharge preceding saccades (Figure 5B).

The reciprocity of the activation of movement and fixation neurons naturally suggests the hypothesis that they engage in a mutually inhibitory relationship, and evidence consistent with this has been obtained, as will be detailed below. It must be emphasized first, though, that, effectively, all of the experiments performed to date have ad- dressed the question of how saccades or eye-head gaze shifts are terminated, which is not necessarily the same as how saccades or gaze shifts are prevented from being initiated (reviewed by Guitton, Bergeron, Choi, \& Matsuo, 2003; Sparks, 2002). Electrical stimulation of the rostral $\mathrm{SC}$, where fixation cells are concentrated, can interrupt saccades in monkeys (Gandhi \& Keller, 1999). This influence could be exerted through more than one circuit. First, fixation neurons could prevent gaze saccades through projections to omnipause neurons that inhibit the saccade generator (e.g., Takahashi, Sugiuchi, Izawa, \& Shinoda, 2005). Second, fixation neurons could inhibit movement neurons elsewhere in the SC (Munoz \& Istvan, 1998); experimental deactivation of the rostral SC results in excessive saccade initiation (Munoz \& Wurtz, 1993). The current body of evidence suggests that fixation neurons are critical for controlling saccade initiation.

The supplementary eye field (SEF) is an area in the dorsomedial frontal cortex that may be considered an ocular motor extension of the supplementary motor area (SMA). In several respects, the SEF seems to parallel the FEF. Neurons in the SEF are responsive to visual or auditory stimulation, and other neurons in the SEF discharge in relation to saccades (e.g., Schall, 1991b; Schlag \& Schlag-Rey, 1987). Other studies have reported more complex functional properties of SEF neurons, including conditional motor learning (Chen \& Wise, 1995), object-centered representation (e.g., Olson \& Gettner, 1999), production of antisaccades (Schlag-Rey, Amador, Sanchez, \& Schlag, 1997), production of sequences of saccades (Lu, Matsuzawa, \& Hikosaka, 2002), and eye-hand coordination (Mushiake, Fujii, \& Tanji, 1996). Saccades can be elicited by low-intensity microstimulation of the SEF (e.g., Schlag \& Schlag-Rey, 1987). The SEF innervates ocular motor centers in the striatum, SC, and brainstem (e.g., Huerta \& Kaas, 1990). However, as will be elaborated below, the SEF seems to play a less essential or potent role in saccade production. Indeed, ablation of the SEF causes only minimal and short-lasting gaze impairments (e.g., Schiller \& Chou, 2000).

The label of anterior cingulate cortex (ACC) refers to a large and heterogeneous part of the cerebral cortex that can be partitioned on the basis of architecture, connectivity, and functional properties (e.g., Bush, Luu, \& Posner, 2000; Paus et al., 1996; Ridderinkhof, Ullsperger, Crone, \& Nieuwenhuis, 2004). Several lines of evidence suggest that the ACC contributes to ocular motor function. Anatomical studies in monkeys have shown dense, reciprocal connectivity between the ACC and the SEF (Huerta \& Kaas, 1990; Luppino, Matelli, \& Rizzolatti, 1990) and a much weaker linkage with the FEF (Huerta, Krubitzer, \& Kaas, 1987; Stanton, Bruce, \& Goldberg, 1993). Saccadic eye movements can be evoked by electrical microstimulation of a region in the upper bank of the cingulate sulcus directly ventral to the SEF, in the CMAr of area 24c (Mitz \& Godschalk, 1989); however, it must be appreciated that this occurs less reliably than in the SEF or FEF. Some involvement of the ACC in the cognitive control of ocular motor behavior in normal human subjects has been reported from functional imaging studies (e.g., Paus, Petrides, Evans, \& Meyer, 1993; Petit, Courtney, Unger- 
leider, \& Haxby, 1998). Also, two human patients with focal lesions in the ACC exhibited deficits in high-order control of gaze (Gaymard, Ploner, Rivaud, Vermersch, \& Pierrot-Deseilligny, 1998).

Single-unit recordings in the ACC of macaques have reported a variety of signals. Some ACC neurons show directional delay activity and activity following errors or omission of reward (Amiez, Joseph, \& Procyk, 2006; Ito, Stuphorn, Brown, \& Schall, 2003; Matsumoto, Matsumoto, Abe, \& Tanaka, 2007; Niki \& Watanabe, 1976, 1979; Shidara \& Richmond, 2002) and to voluntary movement selection based on reward (Johnston, Levin, Koval, \& Everling, 2007; Matsumoto, Suzuki, \& Tanaka, 2003; Shima \& Tanji, 1998). Others show activity specific to the motor set for self-paced movements (Shima et al., 1991); some neurons encode the serial order of movements in sequences and have shown different activity profiles in trial-and-error exploration and routine performance (Procyk, Tanaka, \& Joseph, 2000).

Indirect measures of neural activity in humans have focused discussions of self-monitoring and self-control on the ACC. As will be described in more detail below, a particular event-related potential referred to as the error-related negativity (or $\mathrm{Ne}$ ) is observed when subjects make errors; this component appears to arise in the ACC (Dehaene, Posner, \& Tucker, 1994; Miltner, Braun, \& Coles, 1997). Also, neuroimaging studies have described ACC activation when subjects must inhibit competing responses, apply a new stimulus-response mapping rule, or generate an action under limited or no constraints (e.g., Botvinick, Cohen, \& Carter, 2004; Ridderinkhof et al., 2004). The nature of these signals has been the focus of a great deal of research and is a central concern of this review.

\section{Neural Control of Saccade Initiation}

Response time is characterized by stochastic variability (Luce, 1986). To understand the source of the variability of response time, we have investigated the pattern of activity recorded from movement-related neurons in the FEF. We found that saccadic eye movements were initiated when movement-related activity in the FEF reached a particular level that was idiosyncratic for each neuron but did not vary with response time (Figure 4; see Hanes \& Schall, 1996; see also Lecas, Requin, Anger, \& Vitton, 1986). The same observation was made for the magnitude of the lateralized readiness potential, an event-related potential that precedes movements (Gratton, Coles, Sirevaag, Eriksen, \& Donchin, 1988). The variability in response time was accounted for mainly by variation in the rate of growth of the premovement activity toward the trigger threshold. Thus, the movement-related neural activity in the FEF appears to correspond to an accumulator architecture with variable growth to a fixed threshold (e.g., Carpenter \& Williams, 1995; Ratcliff \& Smith, 2004; Usher \& McClelland, 2001). The origin of the variability in the growth of activity is not known; perhaps it can be accounted for, at least in part, by the state of neuromodulatory systems (e.g., AstonJones, Rajkowski, Kubiak, \& Alexinsky, 1994). Biophysically plausible models demonstrate how such circuits can operate (e.g., Durstewitz, 2003; Lo \& Wang, 2006).

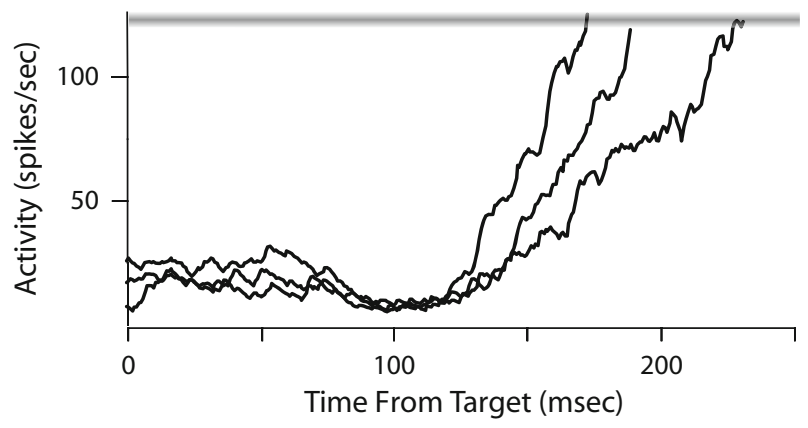

Figure 4. Relationship between movement-related frontal eye field (FEF) activity and saccade initiation. The time course of activation of a single movement-related FEF neuron is shown for three subsets of trials having different saccade latencies. Plots are aligned on target presentation and stop at saccade initiation. The level of activity at which the saccade is triggered (gray bar) is constant across saccade latencies. Variability in saccade latency is accounted for by the time taken by the neural activity to reach the threshold activation.

Although this result indicates how the variability of saccade initiation times can be accounted for by the activation of neurons in the ocular motor pathway, the results do not explain the ability of a subject to control saccade production. A critical characteristic of voluntary control is the ability to withhold planned movements. Thus, can saccades be prepared but not executed? If so, what do the neurons that produce a movement do when the movement is canceled because of the stop signal? A virtue of the countermanding paradigm is that one can determine whether single neurons generate signals that are sufficient to control the production of movements. The logic of the countermanding paradigm establishes two criteria a neuron must meet to play a direct role in the control of movement. First and most obvious, the neuron must discharge differently when a saccade is initiated versus when a saccade is withheld. Second and most important, this difference in activity must occur by the time that the movement is canceled - that is, within the stop signal reaction time.

Two physiological studies in macaque monkeys have described the activity of neurons in the FEF (Hanes, Patterson, \& Schall, 1998) and the SC (Paré \& Hanes, 2003) of monkeys performing the saccade stop signal task. After the target (the go signal) appeared, movement-related activity in both structures began to grow toward the trigger threshold. If the stop signal occurred but the activity happened to reach threshold, a noncanceled error was produced. However, successful canceled trials occurred when the movement-related activity was inhibited so that it did not reach the threshold activation level (Figure 5). This difference in movementrelated activity associated with canceling, as compared with executing, the movement appeared just before the stop signal reaction time had elapsed. Therefore, the activity of these movement neurons in the FEF and SC is sufficient to specify whether or not a saccade will be produced.

A complementary pattern of neural activity was observed in another class of neurons in the FEF and SC called fixation neurons (Figure 5). If eye movements were canceled, fixation neurons that had decreased firing generated a rapid burst 

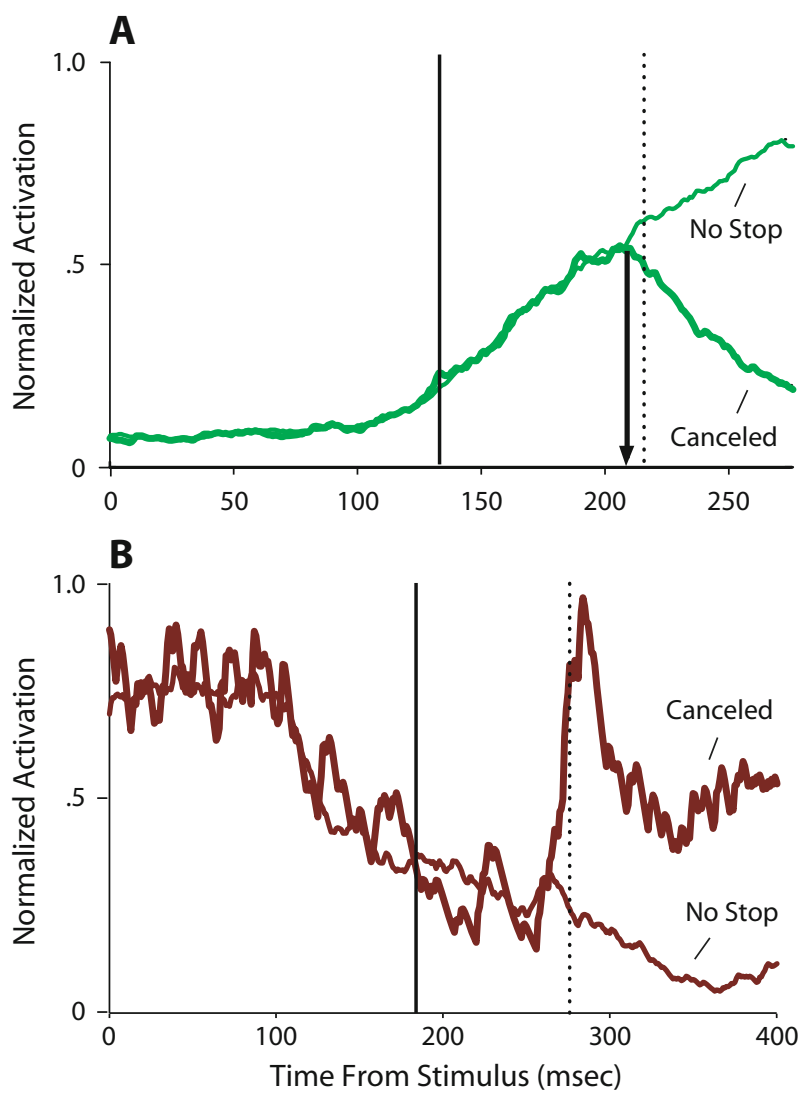

Figure 5. Relationship between frontal eye field (FEF) neural activity and canceling a movement. (A) Normalized activity of FEF movement neurons on trials in which the movement was produced but would have been canceled if the stop signal had been presented (thin green line) is compared with activity on trials in which the planned saccade was canceled because the stop signal appeared (thick green line). The time of the stop signal is indicated by the solid vertical line. The time needed to cancel the planned movement- stop signal reaction time - is indicated by the dashed vertical line. When the movement was canceled, neural activation decayed precipitously immediately before the stop signal reaction time. The time of this significant modulation is termed cancel time and is indicated by the solid vertical arrow. This modulation within the stop signal reaction time demonstrates that this neuron conveys a signal sufficient to control whether the eyes move. (B) Comparison of the normalized activity of FEF fixation neurons when saccades were initiated (thin red line) or canceled (thick red line). The discharge rate of the neuron decreased before and during saccades. When the saccade was canceled, the activation increased sharply before the stop signal reaction time. From "Inhibitory Control in Mind and Brain: An Interactive Race Model of Countermanding Saccades," by L. Boucher, T. J. Palmeri, G. D. Logan, and J. D. Schall, 2007, Psychological Review, 114, p. 381. Copyright 2007 by American Psychological Association. Adapted with permission.

of activity before the stop signal reaction time. The modulation before the stop signal reaction time was never observed in neurons with only visual responses. The different results observed for the different functional classes of neurons is entirely consistent with the fact that movement and fixation neurons in the FEF provide direct input to the brain structures that produce eye movements (Segraves, 1992; Segraves \& Goldberg, 1987; Sommer \& Wurtz, 2000).

\section{Interactive Race Model of Countermanding}

We have just reviewed the evidence that movement and fixation neurons in the FEF and SC (as well as, we think, corresponding neurons in the basal ganglia and thalamus) are modulated in a manner sufficient to be said to control saccade initiation. Does this mean that movement and fixation neurons instantiate the $g o$ and stop processes of the race model that explains behavior obtained in the countermanding task? The formulation of this linking proposition is not trivial (Schall, 2004). One facet of this complexity concerns the central assumption of the race modelnamely, that the finish times of the go and stop processes are independent (Logan \& Cowan, 1984). If the neural circuits that instantiate the go and stop processes consist of interacting movement and fixation neurons, how can interacting neural units produce behavior that appears to be the result of independent processes?

We approached this paradox through simulation of a simple network model consisting of one go unit and one stop unit (Boucher, Palmeri, Logan, \& Schall, 2007). Each unit was a noisy accumulator (Usher \& McClelland, 2001) with the activation of the go and stop units rising to a fixed threshold at variable rates of growth, just like the neurons in the FEF and SC. We contrasted network architectures in which the go and stop units either were independent or interacted with one another through inhibitory connections (Figure 6). The behavioral and neural data used to evaluate the models were those described above from the FEF.

Our approach to modeling was twofold. We first optimized model parameters to the behavioral data - namely, the reaction time distributions and the proportion of canceled trials at each stop signal delay (known as the inhibition function). A particular model architecture was ruled invalid if it could not fit the behavioral data. The next crucial step was to determine whether a particular architecture could predict specific aspects of the underlying neurophysiology. Specifically, for a particular model architecture to be ruled correct, the average activation of the units in the network had to correspond qualitatively and quantitatively to the pattern of activity of neurons that were recorded concomitant with the behavioral data. Qualitatively, a successful model must produce go unit activation accumulating to reach threshold on trials on which a saccade is made in no-stop-signal or noncanceled trials and also a decrease in activation after an initial accumulation when saccades are inhibited on canceled trials. Conversely, stop unit activation must remain off when saccades are made on no-stop-signal trials or noncanceled trials and must become activated when saccades are withheld on canceled trials. Quantitatively, the time of the modulation of the go and stop units in canceled trials, measured relative to the stop signal reaction time (referred to as cancel time), must fall within the range of such times obtained from neurons in the FEF and SC.

The stochastic accumulator instantiation of the independent race model accounted for the behavioral data obtained in this task very well (see also Hanes \& Carpenter, 1999). This is not surprising, given the formal generality of the race model. However, the independent race model could not account for the pattern of activation of the FEF 
A

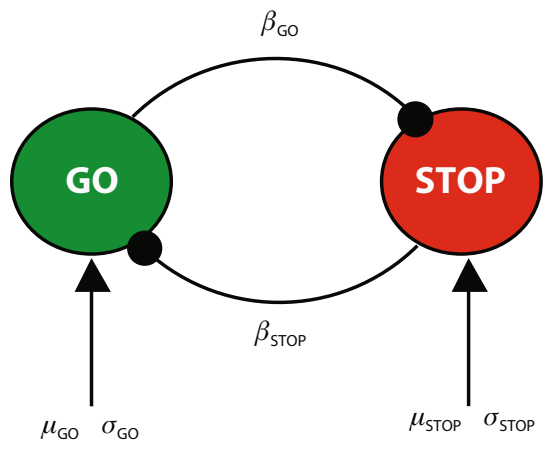

B

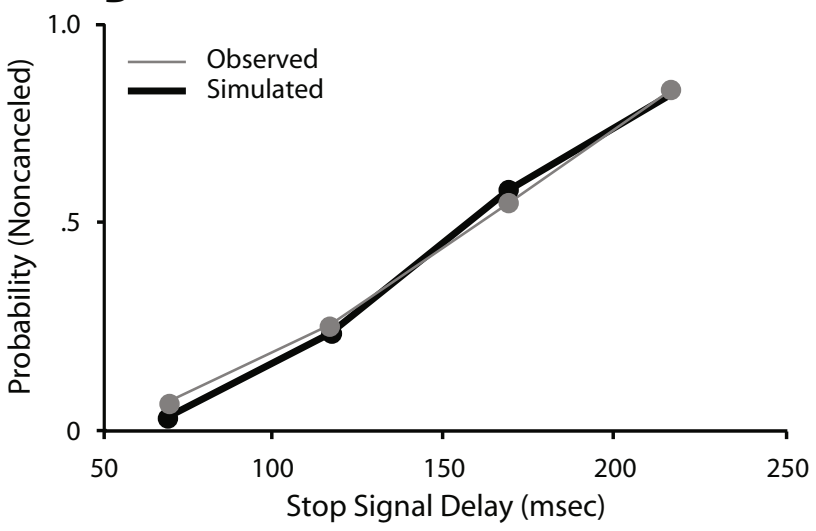

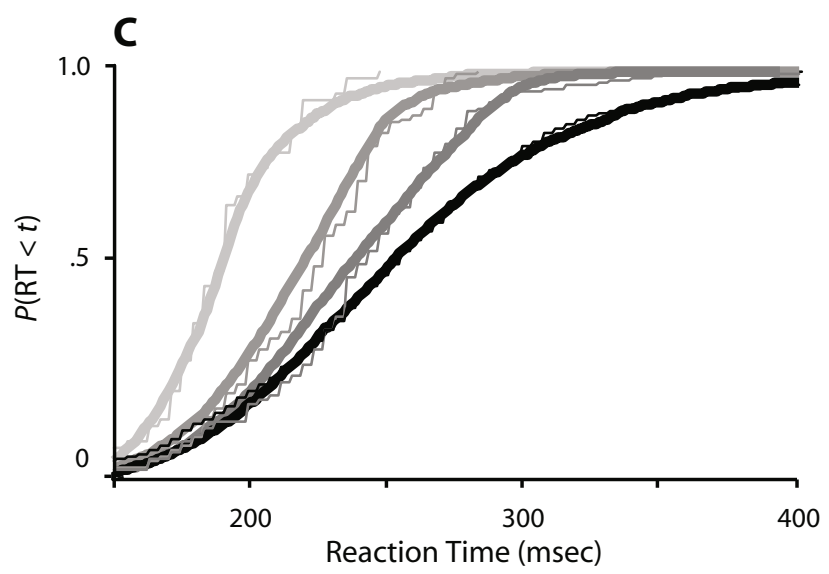

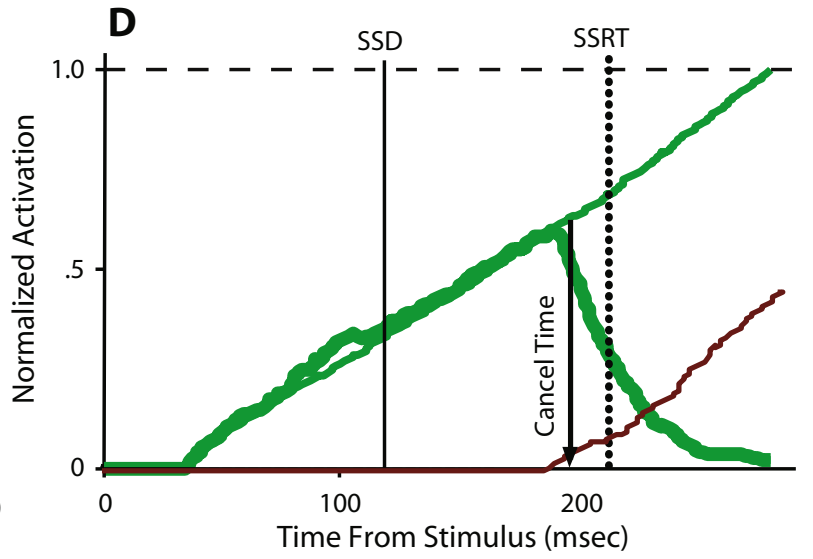

Figure 6. Interactive race model. (A) Architecture of the interactive race model. (B) Observed (gray) and simulated (black) inhibition functions. (C) Observed (thin) and simulated (thick) RT distributions from no-stop-signal and noncanceled trials with progressively longer stop signal delays (SSDs). (D) Average normalized go unit (green) and stop unit (red) activation functions on canceled (thick solid) and latency-matched no-stop-signal trials (thin solid) with stop signal presentation (SSD) and stop signal reaction time (SSRT) indicated. Cancel time is indicated by the downward arrow. Note the pronounced modulation of the go unit before the SSRT on canceled trials, similar to the movement neuron's modulation in activity. From "Inhibitory Control in Mind and Brain: An Interactive Race Model of Countermanding Saccades,” by L. Boucher, T. J. Palmeri, G. D. Logan, and J. D. Schall, 2007, Psychological Review, 114, p. 384. Copyright 2007 by American Psychological Association. Adapted with permission.

or SC neurons. The activation of the go unit reached its threshold on every trial, regardless of trial outcome. In other words, on canceled trials in which, according to the rules of the simulation, a saccade is not produced, the go unit activation reached the threshold because nothing prevented it from doing so.

Obviously, something must prevent the go unit from triggering a saccade, and this is the motivation for the interactive race architecture in which the stop unit can inhibit the go unit. We found that a specific form of interaction between the stop and the go units fit the behavioral data as well as did the independent race architecture (Figure 6). The probability of inhibiting a movement when a stop signal occurs and the specific patterns of the response times on trials with no stop signal and error trials in which the saccade was produced despite the stop signal were accounted for well by this model. Note how the progressively shorter error response times for progressively shorter stop signal delays are fit by the interactive race model. Furthermore, the interactive race model captured the essential aspects of the neural data. First, the go unit activation did not differ between no-stop-signal trials and noncanceled stop signal trials when the threshold was reached at earlier times. Second and importantly, the go unit activation was markedly different in canceled trials, as compared with no-stop-signal trials. In canceled trials, the go unit activation was inhibited because the stop unit became active before the stop signal reaction time. Being inhibited, the go unit activation did not reach the threshold, and thus, no (simulated) saccade was produced. Moreover, the time of this modulation of the go unit and of the stop unit corresponded to the values measured for actual movement and fixation neurons in the FEF and SC. It is important to appreciate that the correspondence between the time of modulation of the model units and of the neurons was not constructed into the model. Instead, it seems to be a necessity for a physical instantiation of the countermanding race model. 
This result, obtained from a fruitful coordination of a task producing a particular pattern of performance, a formal mathematical model, and neurophysiological observations, establishes the plausibility of the linking proposition identifying the go and stop processes with the activity of movement and fixation neurons. Now, gaze-holding neurons are characterized by higher discharge rates during periods of visual fixation - hence, the name fixation neurons - but this attribute was not included in this model because it was not a necessary component of the modulation of the stop unit needed to interrupt the go unit. Every model has boundaries, and we are confident that it should be straightforward to extend the interactive race model to account for this activity, given prior work demonstrating conditions for stability of mutual inhibitory networks (e.g., Lo \& Wang, 2006).

The paradox of how interacting units can give rise to behavior that appears to be the outcome of independent processes is solved by this interactive race model. Using nested model analysis techniques, we discovered two key characteristics of the model parameters necessary to simulate both the behavioral and the neural data. The first requirement is that the inhibition of the stop unit on the go unit must be potent, whereas the inhibition of the go unit on the stop unit must be weak. The need for this asymmetry is apparent when the alternatives are considered. In the extreme case, if the stop unit does not inhibit the go unit (i.e., the independent race architecture), there can be no canceled trials, because the go unit would reach threshold on every trial. On the other hand, if the inhibition of the stop unit on the go unit is weak and gradual, so that the stop unit influences the go unit over a prolonged period, then if the go unit does happen to reach threshold, it does so later than it would if the stop unit had not been active, thereby producing response times that are longer than those observed. The second requirement of the model parameters states that the influence of the stop unit on the go unit must be delayed after the stop signal occurs. This requirement entails that the inhibition of the stop unit must be potent enough to interrupt the go unit, which will have become progressively more active at longer stop signal delays. In other words, the interruption of the go unit by the stop unit is almost an all-or-none event. Thus, the potency of the stop unit inhibition that permits a short period of interaction some time after the stop signal occurs affords the appearance of an independent race between the go and the stop processes.

The race model of response production also provides an account of how speeded errors can occur. If response production were driven exclusively by some representation of the task-relevant evidence in the environment, errors would be explained by failure to represent evidence correctly. However, several lines of research have demonstrated that sensory and memory representations can be veridical even if responses are not produced or are incorrect for the stimuli. For example, in monkeys performing a saccade double-step task with visual search, visual neurons in the FEF locate the new location of the oddball in the search array correctly even when monkeys incorrectly shift gaze to the old location (Murthy, Thompson,
\& Schall, 2001). But if the brain located the new location of the oddball correctly, why was an error made? A plausible answer appeals to the hypothesis that the response production stage can be guided by but operates with some independence from the perceptual stage. In fact, these errors can be corrected very rapidly, even before the brain can register that the gaze shift was an error (Murthy et al., 2007). Moreover, the flexible relationship between perceptual processing and response production is just what is needed to provide for adjustments of speed versus accuracy. Of course, somehow the brain must be able to register what it means to do and effect those adjustments (e.g., Holroyd, Yeung, Coles, \& Cohen, 2005).

\section{Performance Monitoring \\ by the SEF and the ACC}

The findings from the FEF and SC using the countermanding paradigm demonstrate that the preparation of a movement can be a controlled process; it can be canceled if the period of growth of the activation toward the trigger threshold is sufficiently slow. What if errors are made because the movement is not canceled? As has been described above, FEF and SC neurons discharge in the same fashion for errant saccades produced on stop signal trials as for correct saccades produced on no-stopsignal trials. However, to perform the task well, subjects should know when errors are made and should adapt their behavior to minimize future errors. Recall that stop signal task performance varies according to stimulus and performance history. Thus, some part of the brain must monitor the conditions and consequences of action to adjust performance.

We have recorded neural activity in the SEF and ACC of monkeys performing the saccade countermanding task (Ito et al., 2003; Stuphorn, Taylor, \& Schall, 2000). Despite the numerous parallels in anatomical connections, neuronal activation profiles and stimulation effects observed for the SEF and FEF (reviewed by Schall, 1997), we have found that, unlike their counterparts in the FEF, remarkably few neurons in the SEF generate signals that are sufficient to control gaze (see Schall, Stuphorn, \& Brown, 2002). Specifically, neurons in the SEF that are modulated in association with saccade production do not exhibit a reliable threshold. In addition, these neurons in the SEF modulated after the stop signal reaction time on canceled trials, which is too late to exert any control over saccade initiation. These observations are consistent with observations that lesions of the SEF cause only a relatively modest impairment of gaze (Schiller \& Chou, 2000; see also Husain, Parton, Hodgson, Mort, \& Rees, 2003; Parton et al., 2007). On the other hand, following combined ablation of the FEF and the SC, leaving the SEF intact, monkeys cannot produce saccadic eye movements (Schiller, True, \& Conway, 1980). Thus, the impotency of the SEF in affecting saccade initiation seems quite distinct from the clear potency of FEF and SC.

Instead of signals controlling gaze, we found distinct groups of neurons in the SEF that were active after errors, after successful withholding of a partially prepared movement, or in association with reinforcement. These 
three forms of activation could not be explained by sensory or motor factors, so we interpret them as evaluative signals. Although interpreting signals in the ACC in terms of monitoring performance is not novel, this interpretation of the SEF is a new perspective. However, this framework has been supported by new evidence from functional brain imaging studies (Curtis, Cole, Rao, \& D'Esposito, 2005; Nachev, Rees, Parton, Kennard, \& Husain, 2005) and effects of localized lesions (e.g., Parton et al., 2007; Sumner et al., 2007).

Error-related activity. We have found that certain neurons in both the SEF and the ACC exhibit modulation specifically on trials in which a planned movement is not canceled, resulting in no reward's being delivered (an example from the ACC is shown in Figure 7). These neurons did not modulate when rewarded saccades were made on trials with no stop signal, nor were they modulated in stop signal trials resulting in a successfully canceled movement or in relation to delivery of reinforcement. Thus, we interpret this modulation as signaling an error. Furthermore, we found that the latency of the single-unit error signal observed in the SEF preceded that observed in the ACC (Ito et al., 2003). This suggests that the error signals in the SEF and ACC may be somewhat distinct, which would entail that there is not a unitary error signal produced in the medial frontal lobe.

One of the motivations for interpreting this signal from single neurons in terms of error detection is its correspondence with the error-related negativity (ERN; see, e.g., Falkenstein, Hohnsbein, \& Hoormann, 1991; Gehring, Goss, Coles, Meyer, \& Donchin, 1993). This eventrelated potential was the first clear physiological signature of a supervisory control system. Numerous studies have described an ERN following errors, and although some studies have reported no relation of the signal to the correction of errors (e.g., Falkenstein, Hohnsbein, \& Hoormann, 1995; Miltner et al., 1997; Scheffers, Coles, Bernstein, Gehring, \& Donchin, 1996), others have described such a relationship (Debener et al., 2005; Gehring et al., 1993; Kerns et al., 2004). The source generator of the ERN seems centered in the ACC but may include the supplementary motor area located dorsal to the ACC (Dehaene et al., 1994; Garavan, Ross, Kaufman, \& Stein, 2003; Miltner et al., 1997). Furthermore, a medial frontal event-related negativity has also been observed following error feedback. Likewise, certain neurons in the ACC that responded after errors also signaled when reinforcement that had been earned was not delivered (Figure 7).

To establish a stronger link between the neurophysiological findings in monkeys and human event-related potentials, we have measured local field potentials (LFPs) in the ACC of macaque monkeys performing the saccade countermanding task (Emeric et al., 2007). The LFPs at the large majority of sites exhibited greater negative polarity after errors than after rewarded, correct trials (Figure 7). This negative polarity was also observed in occasional unrewarded, correct trials. This shows that the intracranial potential corresponds as well to the feedback-related negativity (e.g., Taylor et al., 2006; Yeung, Holroyd, \& Cohen, 2005). In contrast, when synchronized on the time of pre-
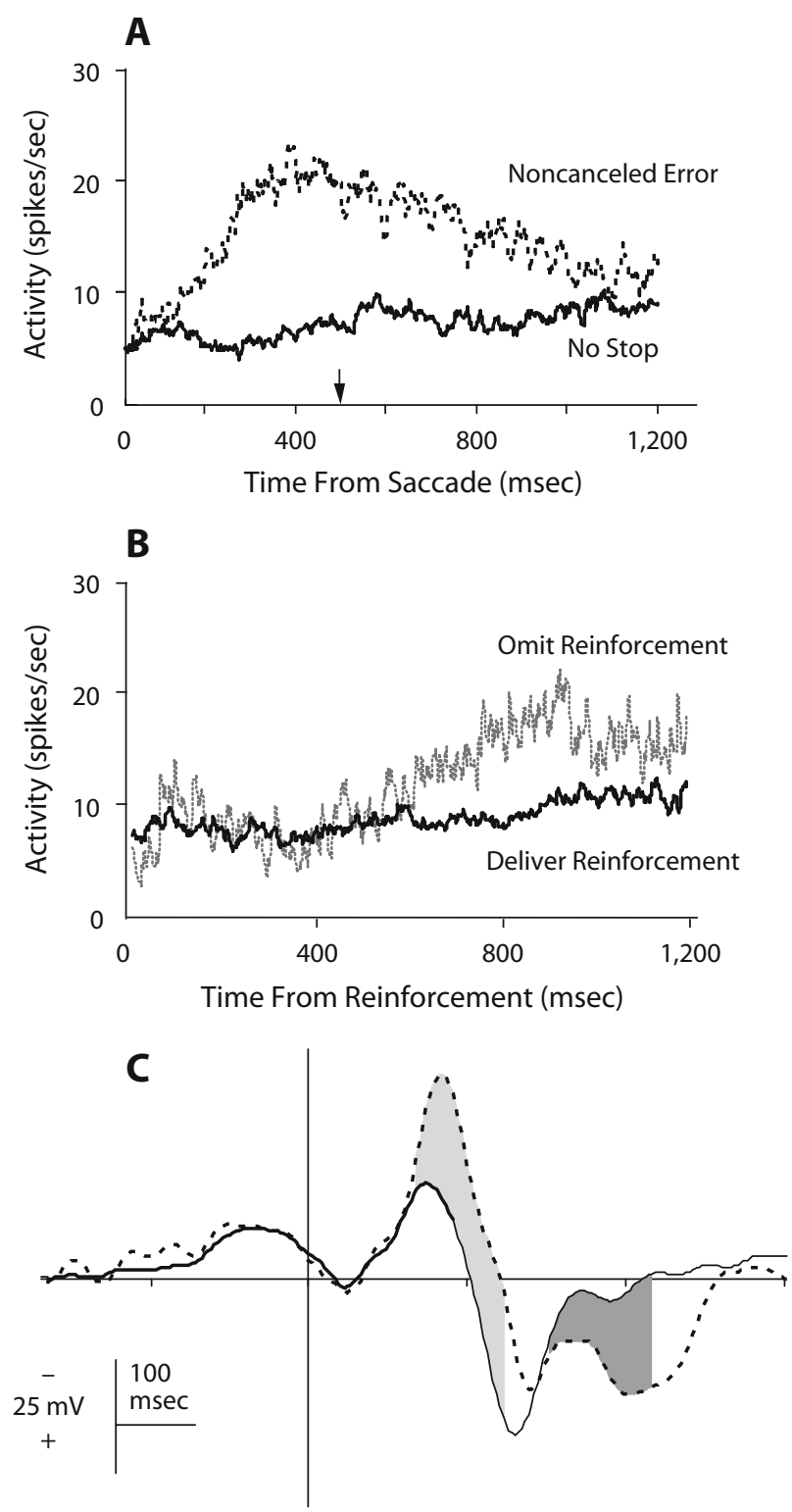

Time From Saccade (msec)

Figure 7. Error-related and feedback-related neural activity. (A) Comparison of activity of an anterior cingulate cortex (ACC) neuron between trials in which the eye movement was made because no stop signal was given (thin line) and trials in which the eye movement was made despite the stop signal (thick dashed line). This neuron discharged following errant, noncanceled saccades, but not correct saccades, in trials with no stop signal. (B) Comparison of activity of the same neuron between correct no-stop-signal trials in which fluid reward was delivered (solid line) or with held (dotted line). This neuron discharged after the interval in which the reward was expected. (C) Intracranial error-related negativity. Local field potential recorded from the ACC in correct trials with no stop signal (solid line) and in noncanceled error trials (thick dashed line). Panel B is from "Performance Monitoring by the Anterior Cingulate Cortex During Saccade Countermanding," by S. Ito, V. Stuphorn, J. W. Brown, and J. D. Schall, 2003, Science, 302, p. 121. Copyright 2003 by the American Association for the Advancement of Science. Adapted with permission.

sentation of the target or stop signal, the LFP was much less polarized. Finally, we obtained no clear evidence that 
the LFP activity in the ACC is sufficient to control the production of gaze shifts during the countermanding task or that response time adjustments on subsequent trials were correlated with the negative polarity on individual trials. Finding error-related and feedback-related intracranial field potentials concomitantly with unit activity in the ACC provides a bridge between the human ERN literature and the monkey neurophysiology literature.

Reinforcement-related activity. On trials with no stop signal, monkeys received positive reinforcement following an accurate saccade to the target. On trials with a stop signal, monkeys earned positive reinforcement when the partially prepared saccade to the target was canceled and fixation was maintained. In this way, the countermanding task provides a novel dissociation of behavior from reinforcement; identical actions (saccades to the target) can yield different outcomes (successful no-stop-signal trials or unsuccessful noncanceled trials). Conversely, different actions (saccades when no stop signal was presented or holding fixation when the stop signal was presented) lead to the same outcome (positive reinforcement). In addition, reinforcement can be withheld on some successful trials.
These conditions permit the distinction between neuronal signals related to producing the behavioral response and those related to the reinforcement of that response.

We observed a population of neurons in the SEF and ACC that were active specifically in rewarded trials with either no stop signal or canceled stop signal trials. For example, Figure 8 illustrates a neuron recorded in the SEF that became active after the saccade. If the saccade was an error, the activity was reduced, but if it was successful, the activity continued to grow during the 800 -msec constant interval until the reinforcement was delivered. This neuron, representative of SEF neurons, exhibited an additional modulation following receipt of the reinforcement. To extend the performance of the monkeys, primary juice reinforcement was delivered on only a fraction of successful trials, but a secondary tone reinforcement was delivered on every successful trial. The neurons in the SEF were modulated equivalently whether the secondary reinforcer was delivered alone or in concert with the primary reinforcer. This neural concomitant of the anticipation and receipt of reinforcement can be interpreted as a direct signal of the receipt of reinforcement. This interpretation is
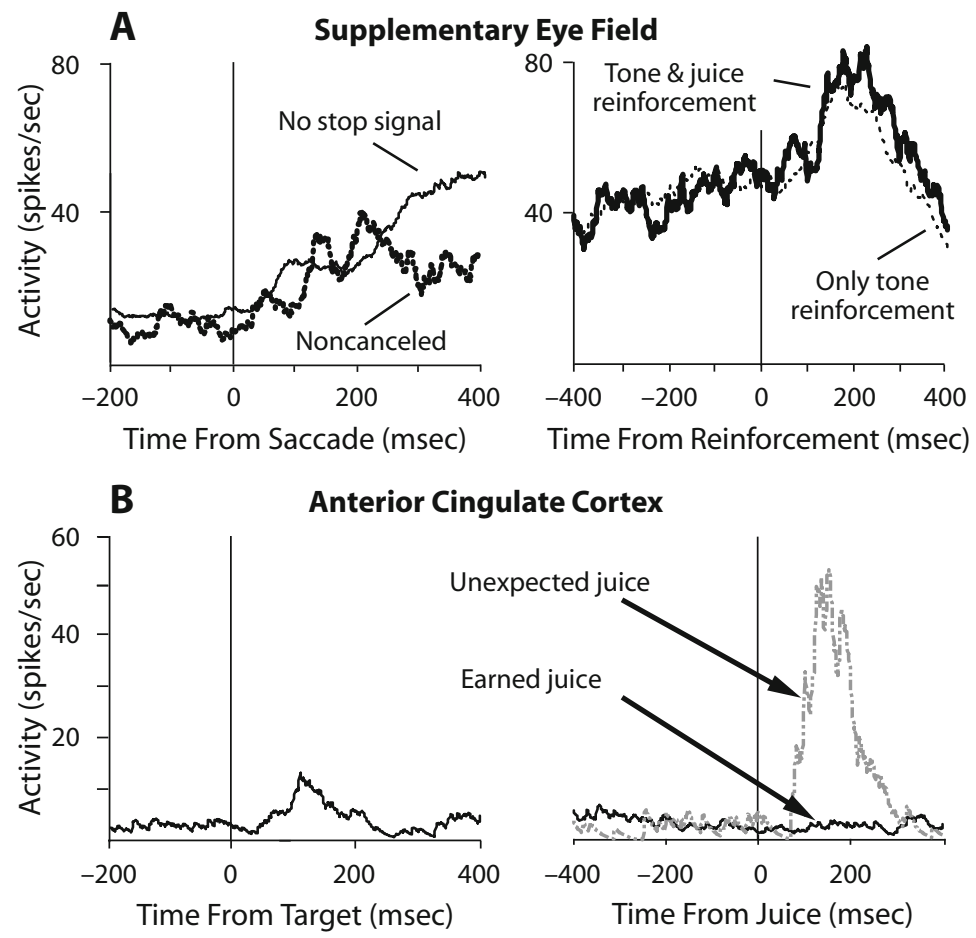

Figure 8. Reinforcement-related neural activity in the supplementary eye field (SEF) and anterior cingulate cortex (ACC). (A) Left panel: Activation of an SEF neuron grew after successful no-stop-signal trials (thin line) but was reduced in noncanceled trials (thick dotted line). Right panel: Activation was elevated while the monkey awaited reinforcement and peaked after delivery of primary plus secondary (thick line) or only secondary (thin line) reinforcement. (B) Left panel: The response of an ACC neuron in response to a visual target during no-stop-signal trials. Right panel: Activation of the same neuron following delivery of free, unexpected juice (red line), but not following earned juice (black line). Panel A was adapted from "Performance Monitoring by the Supplementary Eye Field," by V. Stuphorn, T. L. Taylor, \& J. D. Schall, 2000, Nature, 408 , p. 859. Copyright 2000 by Nature Publishing Group. Adapted with permission. 
supported by the fact that previous studies have identified neural activity with reinforcement in the SEF (Amador, Schlag-Rey, \& Schlag, 2000).

The population of reinforcement-related neurons in the ACC was more diverse than that observed in the SEF (see also Amiez et al., 2006; Shidara \& Richmond, 2002). Some resembled the neurons recorded in the SEF, responding to the secondary tone reinforcer as well as to the primary juice reinforcer. However, other neurons in the ACC responded only to the primary juice reward, both when it was earned and when it was delivered unexpectedly, but not to the secondary reinforcer. Also, unlike what we observed in the SEF, still other ACC neurons responded only to noncontingent, unexpected juice reward (Figure 8). In fact, some of these also showed an apparent visual response. This pattern of activity resembles closely the signals produced by brainstem dopamine neurons (e.g., Schultz, 2007). Taken together, these results imply that the reinforcement signal in the SEF is more abstract, whereas that in the ACC is more closely related to the properties of the reinforcer. Moreover, the existence of these signals in the medial frontal cortex helps substantiate models of executive function that are based on dopaminergic learning signals transmitted to the ACC (e.g., Holroyd \& Coles, 2002; Holroyd et al., 2005).

Conflict-related activity. A third population of neurons in the SEF was distinguished from the error and reinforcement neurons. These neurons exhibited an elevated discharge rate specifically during stop signal trials in which the saccade was correctly canceled, but the modulation occurred after the stop signal reaction time had elapsed (Figure 9). Thus, this modulation cannot be involved in inhibiting the movement, because it occurred too late. Our interpretation of the signal produced by these neurons is motivated and guided by the hypothesis that the medial frontal cortex monitors response conflict that arises when mutually incompatible processes are activated simultaneously but cannot both run to completion (e.g., Botvinick, Braver, Barch, Carter, \& Cohen, 2001; Yeung, Botvinick, \& Cohen, 2004). This hypothesis has been offered as an exclusive alternative to the hypothesis that the medial frontal lobe only detects errors, and a great deal of research has pitted these alternative hypotheses against one another, with new perspectives on the nature of these monitoring signals emerging (e.g., Brown \& Braver, 2005). We will develop the view that these hypotheses are not mutually exclusive; indeed, if distinct populations of neurons signal error, feedback reinforcement, and response conflict, it seems that each hypothesis has merit.

This reconciliation depends on whether the third group of neurons actually signal conflict. The answer to this requires specifying what conflict can occur in the saccade stop signal task. During the saccade countermanding task, gaze-shifting and gaze-holding neurons are activated concurrently when movements are canceled, but not when the movements fail to be canceled (Hanes et al., 1998; Paré \& Hanes, 2003). Because they are mutually incompatible, coactivation of the gaze-holding and gaze-shifting systems engenders conflict, according to the hypothesis. Furthermore, the magnitude of the conflict should be
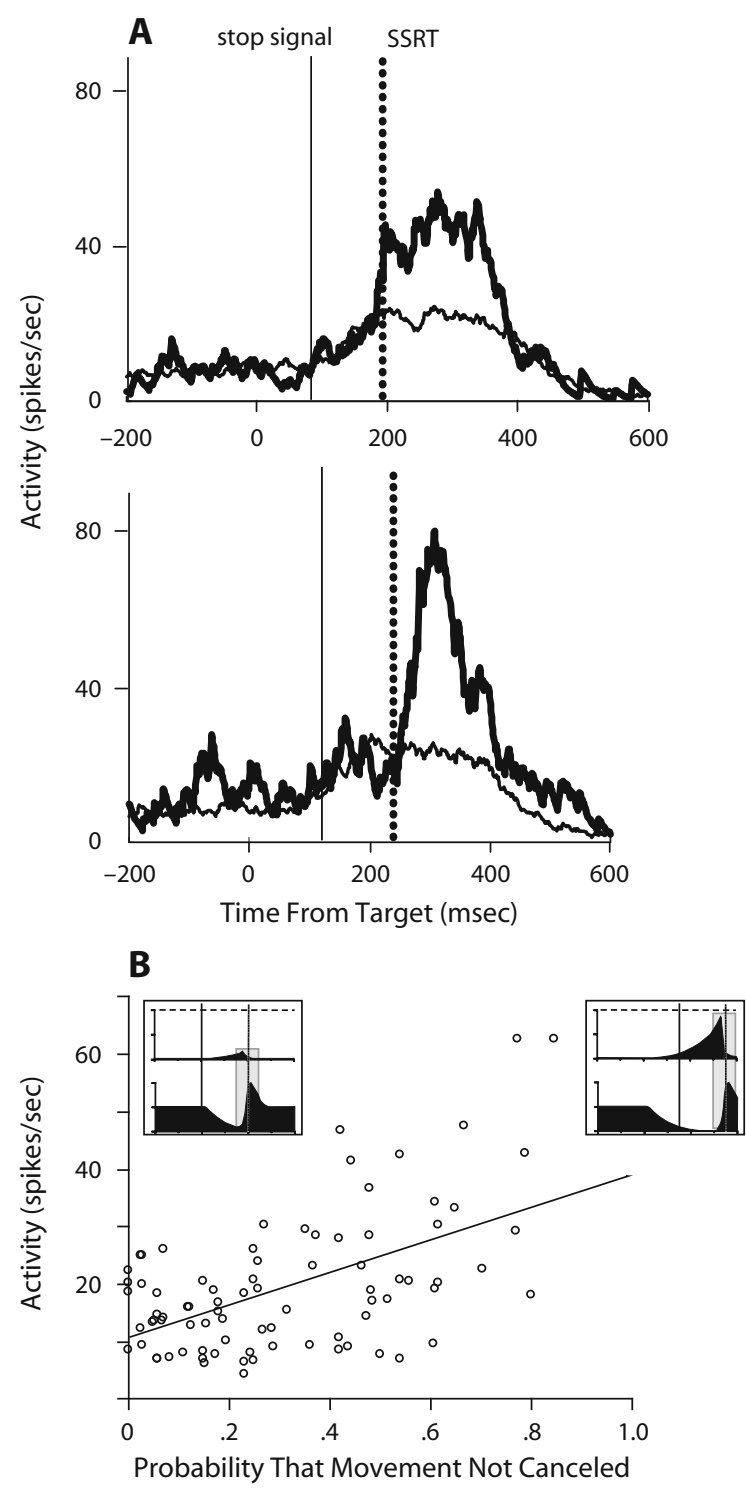

Figure 9. Conflict-related neural activity. (A) Comparison of activity between trials in which the movement was canceled (thick line) and trials in which the movement was produced but would have been canceled if the stop signal had been presented (thin line). The top panel shows data from a shorter stop signal delay $(93 \mathrm{msec})$ in which the monkey canceled the movement on $97 \%$ of the stop signal trials. The lower panel shows data from a longer stop signal delay $(144 \mathrm{msec})$ in which the monkey canceled the movement on $73 \%$ of the stop signal trials. The time of the stop signal and the estimated stop signal reaction time are shown. This neuron was activated after the movement had been canceled, so the modulation could not play a direct role in canceling the movement. (B) The magnitude of activation increased with decreasing probability of canceling the movement. This parallels the amount of coactivation of movement-related and fixation neurons in the frontal eye field and superior colliculus. Inset panels illustrate state of activation of gaze-shifting neurons (top) and gaze-holding neurons (bottom). Conflict corresponds to the magnitude of coactivation of mutually incompatible processes. Conflict is lower on trials with low failure probability (left inset) than on trials with high failure probability (right inset). From "Performance Monitoring by the Supplementary Eye Field," by V. Stuphorn, T. L. Taylor, and J. D. Schall, 2000, Nature, 408, p. 859. Copyright 2000 by Nature Publishing Group. Adapted with permission. 
proportional to the magnitude of the coactivation of the gaze-holding and gaze-shifting neuron pools. Note that the probability of canceling a planned eye movement in the countermanding task is dictated by the balance of activation of gaze-holding and gaze-shifting neurons, since movements are canceled only if the gaze-shifting activation does not reach the threshold to trigger the movement because it is countered by the gaze-holding activation. Thus, the probability of failing to cancel a partially prepared saccade increases as gaze-shifting activation grows. Accordingly, as the probability of failing to cancel the saccade increases, the combined magnitude of gaze-shifting and gaze-holding activation sufficient to cancel a planned movement will be higher, resulting in more conflict.

This measure of processing conflict corresponds to the variation in the magnitude of the neural modulation observed in these SEF neurons (Figure 9). The magnitude of the modulation of these neurons when saccades were canceled increased as the probability of not canceling that saccade increased. Thus, certain neurons in the SEF modulate in a manner sufficient to signal the conflict between gaze holding and gaze shifting that occurs when saccades are canceled in the countermanding task (see also Nakamura, Roesch, \& Olson, 2005).

The putative conflict-related modulation observed in SEF neurons exhibits one characteristic that may appear different from those in previous reports (Botvinick et al., 2001; Yeung et al., 2004). In particular, whereas the conflict signals in the monkey SEF occurred after the response was canceled, the conflict signals described by Botvinick et al. (2001) and Yeung et al. (2004) occurred well before responses. Yeung et al. (2004) argued that conflict activity happening before response onset is reflected in the $\mathrm{N} 2$ and that conflict activity occurring after the response is reflected in the ERN. This apparent difference of timing obviously requires further investigation; however, some tentative observations can be made. First, because stop signal reaction time measures the time at which the responses that would have been made were canceled, the conflict signal observed in the SEF occurs at the time that the canceled saccades would have been made. In other words, the signal may not be delayed. Second, even if the signal is delayed, some of that delay may result from the latency of transmission and integration of gaze-holding and gaze-shifting signals in the SEF. Finally, without a much better understanding of how eventrelated potentials recorded extracranially relate to neural spiking, it is hazardous to draw too firm conclusions about these relationships.

Now, surprisingly, we found no neurons in the ACC signaling conflict (Ito et al., 2003), nor did we find LFPs modulated in proportion to the amount of conflict (Emeric et al., 2007). This observation is not consistent with the hypothesis that the general function of the ACC is to signal response conflict. It is possible, though, that a signal of conflict when saccade preparation is interrupted may be present in the SEF, but not in the ACC, because the SEF, unlike the ACC, is densely connected with ocular motor structures, such as the FEF and SC. Also, conflict signals may have been observed in the human, as opposed to the macaque, ACC in previous studies because of differences in species, tasks, or effector. The combination of species and task differences can be resolved only through further investigation. Alternatively, we should remain open to the possibility that previous reports of a conflict signal in the human ACC may admit to alternative interpretations (e.g., Brown \& Braver, 2005) or may be in error (e.g., Roelofs, van Turennout, \& Coles, 2006).

We suspect that differences of effector may be more plausible. In the first place, only one saccade can be made at a time, but bimanual movements, for example, are common. In the second place, sensitivity to limb posture is much more pronounced than is sensitivity to eye position. Therefore, conflict between competing bimanual responses may be more common than conflict between competing saccade responses. Nevertheless, activation associated with eye movements has been observed in the caudal ACC (O'Sullivan, Jenkins, Henderson, Kennard, \& Brooks, 1995; Paus et al., 1993; Petit et al., 1993), and ACC lesions impair high-order control of gaze (Gaymard et al., 1998). Finally, the presence of conflict cells in the SEF, but not in the ACC, in monkeys is consistent with reports that locate conflict foci more dorsally in the preSMA and error foci more ventrally in the ACC (e.g., Braver, Barch, Gray, Molfese, \& Snyder, 2001; Garavan et al., 2003; Kiehl, Liddle, \& Hopfinger, 2000; Ullsperger \& von Cramon, 2001; but see Ridderinkhof et al., 2004).

Perhaps the diverse kinds of neural signals that we have observed in the SEF and ACC may provide a reconciliation of these competing hypotheses. On the one hand, we found that neurons exhibiting error-related activity were not active on trials in which conflict between gaze-shifting and gaze-holding was most pronounced (i.e., on trials in which the planned movement was canceled). One the other hand, error-related activity was observed on trials in which no conflict was present because the gaze-holding neurons were not modulated (i.e., on trials in which the movement was produced despite the stop signal; see Hanes et al., 1998; Stuphorn et al., 2000). This indicates that the errorrelated and conflict-related signals may arise from distinct populations of neurons in the medial frontal lobe. If this is so, the search for an exclusive distinction between errorbased and conflict-based models may be misguided.

\section{Influence of the Medial Frontal Lobe on Performance}

As soon as error-monitoring signals were discovered, their relationship to error correction was explored (Gehring et al., 1993). Some studies have described covariation between error and conflict signals and performance adjustments (Debener et al., 2005; Kerns et al., 2004), whereas others have reported no relation of the signal to the correction of errors (e.g., Falkenstein et al., 1995; Miltner et al., 1997; Scheffers et al., 1996). Moreover, just how medial and lateral frontal (and other) areas interact to perform executive control has not been elucidated, in part because noninvasive measures cannot provide data about mechanism. Thus, the specific mechanism(s) by which the medial frontal cortex exercises control is unknown. The medial frontal cortex could activate particular repre- 
sentations in the lateral prefrontal cortex, or it could just modulate the strength of existing representations without changing content. A modulation of existing representations in response structures by medial frontal areas is a fair summary of what happens when monkeys produce antisaccades. Activity in the SEF is elevated for antisaccades, relative to prosaccades (Amador, Schlag-Rey, \& Schlag, 2004), whereas activity in the FEF and SC is reduced (Everling \& Munoz, 2000; Everling, Dorris, Klein, \& Munoz, 1999; but see Sato \& Schall, 2003). Also, damage to the human SEF resulted in self-monitoring deficits (Husain et al., 2003; Parton et al., 2007), and an fMRI signal occurs in the SEF when subjects change plans during conflict (Nachev et al., 2005).

The SEF, but not the ACC, can influence saccade production through at least five anatomical pathways. First, the SEF projects to the FEF (Huerta \& Kaas, 1990). Second, the SEF projects directly to the SC (e.g., Huerta \& Kaas, 1990). Third, the SEF projects to the caudate nucleus (Parthasarathy, Schall, \& Graybiel, 1992), which is known to contribute to adjustments of saccade latency according to trial history (Lauwereyns, Watanabe, Coe, \& Hikosaka, 2002). Fourth, the SEF projects to the locus coeruleus (Huerta \& Kaas, 1990), which has been implicated in controlling response time (Aston-Jones \& Cohen, 2005). Fifth, the SEF can affect saccade latency through direct projections to the brainstem omnipause neurons (Huerta $\&$ Kaas, 1990). Although these connections are not potent enough for the SEF to produce saccades directly (Schiller et al., 1980), we hypothesize that these connections enable the SEF to influence saccade generation by providing biasing signals to the ocular motor system.

To test this hypothesis, we examined whether intracortical microstimulation of the SEF influenced performance in the countermanding task (Stuphorn \& Schall, 2006). Electrical stimulation was delivered simultaneously with the presentation of the stop signal, at a current level well below the threshold for eliciting a saccade. The influence of this stimulation on performance was measured by comparing the fraction of noncanceled trials with and without stimulation. The evidence was quite clear that microstimulation of nearly all sites in the SEF improved performance by reducing the fraction of noncanceled saccades, resulting in a delayed inhibition function (Figure 10). This was a general effect, occurring for both contraversive and ipsiversive saccades. To determine how the electrical stimulation enhanced monkeys' ability to inhibit saccades, stimulation was delivered on some trials with no stop signal. Stimulation in this context caused an increase in saccade latency; this delaying of the go process allowed more time for the stop process to finish first, thereby improving performance.

We were surprised to discover that this influence of intracortical microstimulation on saccade response time depended on the task context. We collected control data while the monkeys performed a simple visually guided saccade task, without the stop signal. Stimulation in this context caused shorter response times, in contrast to the elongated response times that were produced within the context of the countermanding task. How this contextual dependence occurs is not clear at all, but the fact that it does reinforces the interpretation that the effect of the stimulation is executive in nature.

It is possible that the microstimulation served as an enhanced stop signal through another modality; redundant stop signals do reduce stop signal reaction time (CavinaPratesi, Bricolo, Prior, \& Marzi, 2001). However, this does not explain how the effect would vary across sites within the SEF or how opposite effects on saccade latency could occur when visual stop signals occur. Furthermore, in most of the stimulation experiments, microstimulation occurred infrequently in trials with no visual stop signal, weakening the association between the visual stop signal and microstimulation. It is also possible that the stimula-
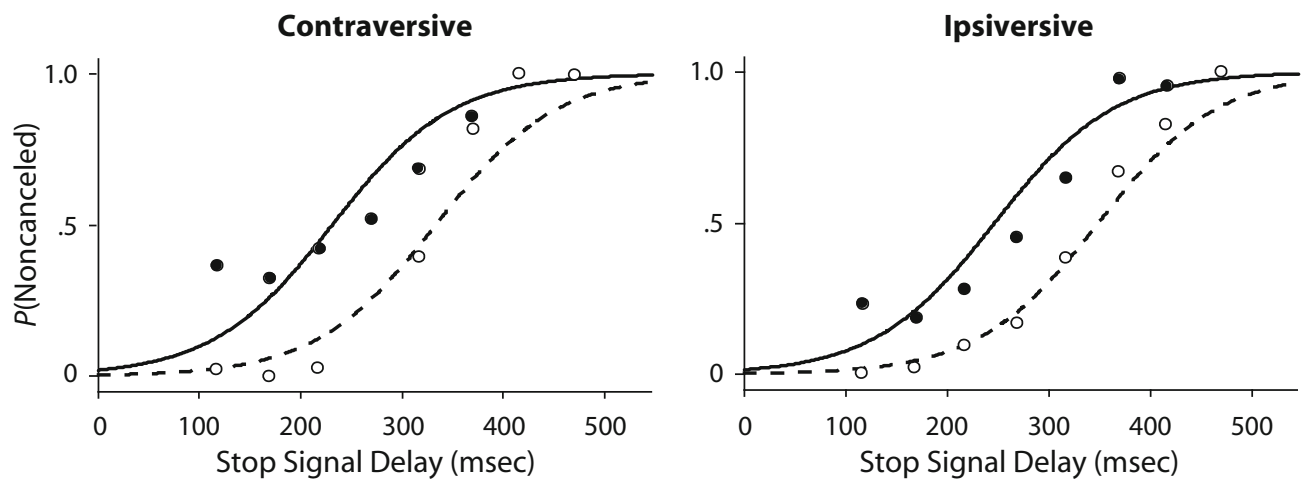

Figure 10. Effect of weak microstimulation of the supplementary eye field (SEF) on saccade countermanding performance with stimulation for contraversive and ipsiversive saccades: Plot of probability of failing to cancel the saccade following the stop signal on trials without (filled circles) and with (open circles) microstimulation of a representative site in the SEF. The curves are maximum likelihood fits of a logistic regression function with stop signal delay and presence (solid line) or absence (dotted line) of microstimulation as statistically significant factors. The rightward shift of the curve on trials with microstimulation indicates that the monkey was better able to withhold the planned movement. From "Executive Control of Countermanding Saccades by the Supplementary Eye Field," by V. Stuphorn and J. D. Schall, 2006, Nature Neuroscience, 9, p. 926. Copyright 2006 by Nature Publishing Group. Adapted with permission. 
tion increased the monkeys' attention in the task. In fact, this is just what many authors suggest that executive control does. Of course, referring to attention does not explain how the effect on performance is accomplished.

\section{Executive Control of the Interactive Race Model With Conflict}

To gain deeper insights into the mechanisms of executive control, we have begun to explore how an executive control module can influence the interactive race model to adapt performance according to trial history (Boucher, Logan, Palmeri, \& Schall, 2006). This executive module could use error, feedback, or conflict as the control signals. As a first step, we are exploring how conflict can be used for self-control. The motivation for this is based on the following observations. First, humans and monkeys lengthened their response times most after stop signal trials in which they successfully canceled their response (Figure 2). Second, the neurons in the SEF seeming to signal conflict do so specifically in canceled trials in which the coactivation of movement and fixation neurons is greatest (Figure 9). We can apply the same definition of conflict to the activation of the go and stop units of the interactive race model. Third, stimulation of the SEF improved performance by increasing response time. Response time can be adjusted in the interactive race model by changing either the starting baseline or the rate of growth of the go unit.

Thus, we have developed a model of executive control of the interactive race with the following features. The amount of conflict ( $g o$ unit activation $\times$ stop unit activation) on trial $N$ is calculated by taking the integral of the conflict signal as it unfolds over time throughout the trial. This integration begins when the stop unit becomes activated (before this, the stop unit value is zero, making the conflict value zero) and continues in canceled trials until the go unit returns to the baseline level after being inhibited by the stop unit or in noncanceled trials until the go unit reaches the threshold. This conflict value is used to adjust by some fraction either the baseline or the rate of accumulation of the go unit on trial $N+1$, as has been suggested previously (e.g., Jones, Cho, Nystrom, Cohen, \& Braver, 2002). This preliminary version of the model does not seek to account for the timing of expression of the conflict signal in the SEF.

The plausibility of this measure is demonstrated by the observation that the magnitude of the conflict measure derived from the model on simulated canceled trials varies with the probability of canceling (Figure 11A) in the same manner as does the activity of the SEF neurons (Figure 9B). The next step was to specify how conflict on trial $N$ would influence the go unit on trial $N+1$. We used the formulation of Botvinick et al. (2001), through which variations of conflict were translated into systematic variations of either baseline or rate of accumulation. Varying the rate of accumulation did not fit the data, but varying the baseline value did, so we will describe that result. A baseline activation value was added to the go unit to provide dynamic range in which to adjust the accumulation to the fixed threshold. A baseline offset value $\left(\Delta B_{\mathrm{GO}}\right)$ was calculated for each successive trial according to the following relationship:

$$
\begin{aligned}
\Delta B_{\mathrm{GO}}(N+1)= & \lambda \cdot \Delta B_{\mathrm{GO}}(N) \\
& +(1-\lambda) \cdot[A \cdot \operatorname{conflict}(N)+B],
\end{aligned}
$$

where $\lambda$ ranges between 0 and 1 , so that the control signal is exponentially weighted on the basis of a certain number of previous trials, and $A$ and $B$ are just scaling parameters. This baseline offset was subtracted from the baseline value of the previous trial so that if conflict was higher, a larger baseline offset was subtracted, resulting in more accumulation and, thus, more time necessary to reach the threshold. The interactive race model with this executive control module was optimized to fit the inhibition functions, as well as the response time distributions, for no-stop-signal trials and for noncanceled trials sorted according to whether the previous trial was a no-stop-signal trial, a canceled stop signal trial, or a noncanceled stop signal trial. This conflict-controlled interactive race model fit both the inhibition functions (Figure 11B) and the response time distributions (Figure 11C). A plot of the mean baseline of the go unit as a function of previous trial type shows the pattern and amount of modulation of the start of the accumulation to the fixed threshold of 1,000 units (Figure 11D). In particular, trials with the greatest amount of conflict, the canceled trials, were followed by the lowest baseline, which resulted in the longest response times, permitting the stop unit more time to interrupt the accumulation of the go unit. Adjustments of saccade latency through variation of baseline firing rates have been observed (e.g., Dorris \& Munoz, 1998; Lauwereyns et al., 2002).

The parsimony of the model and the quality of the fit to the data are compelling, but it must be regarded as provisional. Further research is needed to explore whether this is the only way that a measure of conflict can influence countermanding performance and also to explore whether error and reinforcement prediction signals can be equally effective.

\section{Summary and Avenues for Future Research}

The research reviewed in this article can be organized by the theoretical framework illustrated in Figure 12. Our findings indicate that neurons in the FEF, SEF, and ACC can be mapped onto the central elements of current models of executive control consisting of a response production module and a monitoring module. As has been reviewed above, the strongest anatomical connections are between the FEF and the SEF and between the SEF and the ACC, with much weaker connectivity between the FEF and the ACC. This suggests that the SEF may function as an intermediary between the ocular motor system and cingulate representations of error, feedback, reinforcement, and possibly, response conflict and gaze control. The red arrows indicate the hypothesized functions of each area, and the diagram beneath highlights the mechanistic relationships by which those functions may be accomplished. The FEF (as part of a network including the SC, basal ganglia, thalamus, and brainstem) corresponds to the response module, and the SEF with the ACC constitutes 


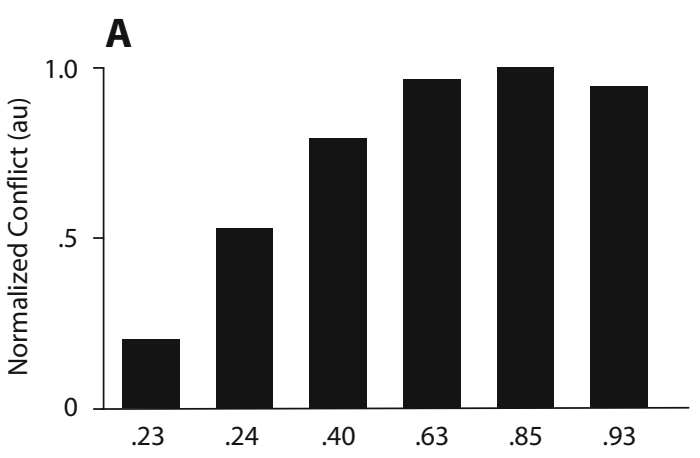

Probability That Movement Not Canceled
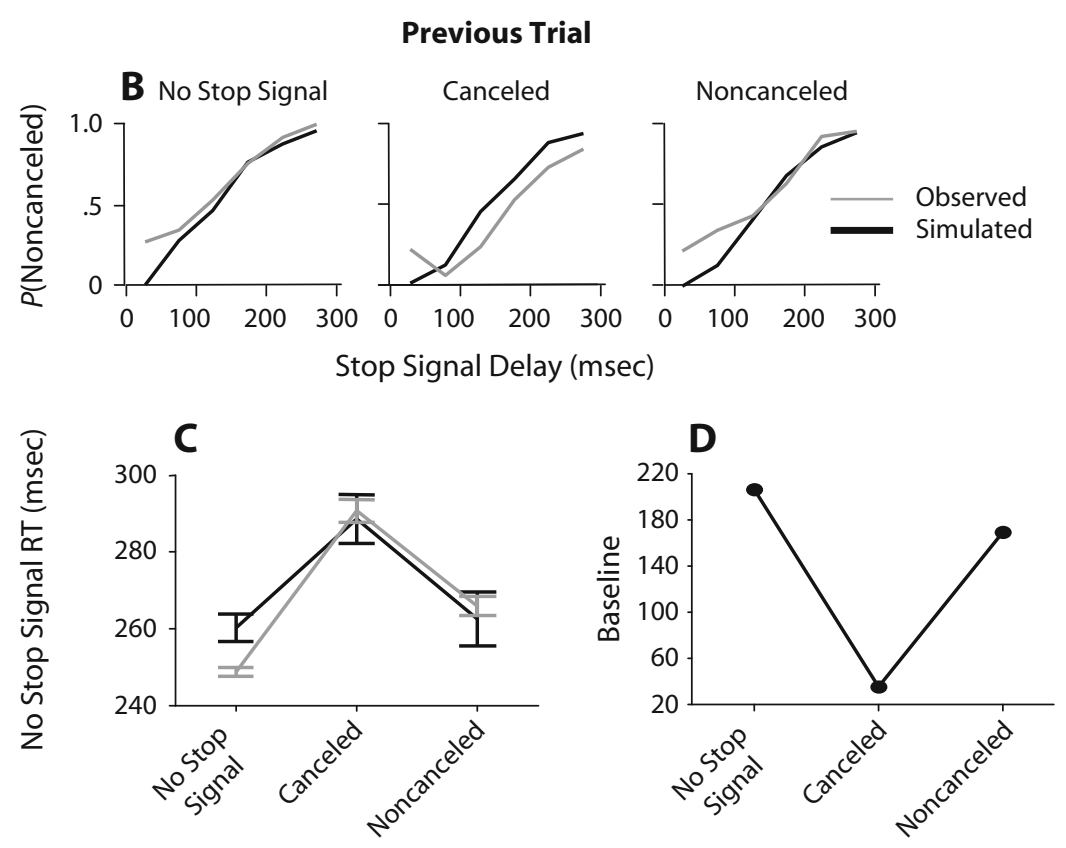

Previous Trial Type

Figure 11. Executive control of the interactive race model. (A) Average amount of conflict generated as a function of the probability that a movement was not canceled. This plots the mathematical product of the activation of the go unit and the stop unit (au, arbitrary units). (B) Simulated (black line) and observed (gray line) inhibition functions based on whether the previous trial was a no-stop-signal trial (left), a canceled trial (middle), or a noncanceled trials (right). (C) Simulated (black line) and observed (gray line) mean reaction time (RT) on no-stop-signal trials as a function of previous trial type. (D) Simulated baseline level of the $g o$ unit as a function of previous trial type. Threshold value was 1,000 .

the executive module. The FEF responds to stimuli and controls the production of saccadic responses. The interactive race model shows that saccade countermanding can be accomplished by go and stop units with stochastic accumulation (rate of growth with mean $\mu$ and standard deviation $\sigma$ ) and mutual inhibition (strengths given by $\beta$ ). A saccade is produced if the go unit activation reaches a threshold. Presentation of a stop signal activates the stop unit after a delay. If the go unit has reached threshold before the stop unit is active, an error noncanceled saccade is produced. If the go unit is below threshold when the stop unit becomes active, the stop unit potently inhibits the go unit, as is illustrated in the figure. The pattern of activation of go and stop units optimized to fit performance corresponds precisely to the activity of movement and fixation neurons in the FEF and SC.

In contrast to the FEF, the SEF does not control saccade initiation but, instead, signals when errors are made, when reinforcement is anticipated, and when conflict between gaze-shifting and gaze-holding occurs. Likewise, the ACC signals errors and reinforcement but, apparently, not conflict in this task. These signals correspond to the elements of the major theories of executive control, as diagramed in the figure. A measure of conflict can be derived from the coactivation of go and stop units indicated by converging inputs on conflict unit. In addition, a measure of error or 


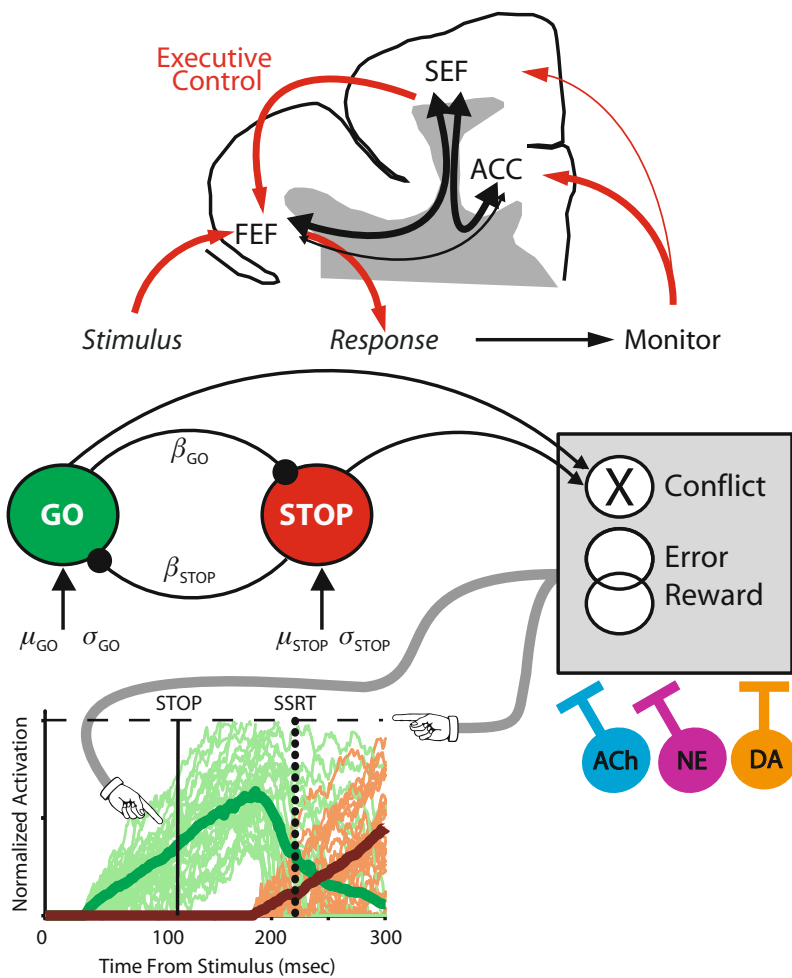

Figure 12. Diagram of theoretical framework. For details, see the text.

reward feedback can be derived from dopamine signals from the brainstem (e.g., Holroyd \& Coles, 2002; Holroyd et al., 2005; Schultz, 2007). Beyond just monitoring when error, reinforcement, and conflict occur, the SEF is capable of doing something about it. Intracortical microstimulation of the SEF with low currents improves saccade countermanding performance by selectively increasing saccade latency. The detailed understanding we have obtained about how saccade initiation is controlled affords very specific hypotheses about how executive control is exerted, as suggested by the pointing fingers in the figure. On the one hand, response time could be adjusted through changes in the baseline activation or the threshold of activity that triggers movements. On the other hand, response time could be adjusted through changes in the rate of change of the activity of movement and fixation neurons. Such adjustment could be effected through direct connections from the SEF or by the norepinephrine, cholinergic, or dopamine systems.

The detailed understanding of neuroanatomy and neurophysiology, coupled with inspiration from cognitive models of performance, can frame the next generation of experiments to elucidate just how the brain does what it means to do.

\section{AUTHOR NOTE}

Our research has been supported by NSF Grant BCS0218507, by NIH Grants R01-MH55806, P30-EY08126, and F32-EY016679, and by Robin and Richard Patton through the E. Bronson Ingram Chair of Neuroscience. We thank Melanie Leslie for comments on previous versions of the manuscript. Correspondence concerning this article should be addressed to J. D. Schall, Center for Integrative and Cognitive Neu- roscience, Vanderbilt University, 111 21st Avenue South, Nashville, TN 37240 (e-mail: jeffrey.d.schall@vanderbilt.edu).

\section{REFERENCES}

Amador, N., Schlag-Rey, M., \& Schlag, J. (2000). Reward-predicting and reward-detecting neuronal activity in the primate supplementary eye field. Journal of Neurophysiology, 84, 2166-2170.

Amador, N., Schlag-Rey, M., \& Schlag, J. (2004). Primate antisaccade: II. Supplementary eye field neuronal activity predicts correct performance. Journal of Neurophysiology, 91, 1672-1689.

Amiez, C., JosePh, J. P., \& ProcyK, E. (2006). Reward encoding in the monkey anterior cingulate cortex. Cerebral Cortex, 16, 1040-1055.

Aston-Jones, G., \& COHEN, J. D. (2005). An integrative theory of locus coeruleus-norepinephrine function: Adaptive gain and optimal performance. Annual Review of Neuroscience, 28, 403-450.

Aston-Jones, G., Rajkowski, J., Kubiak, P., \& Alexinsky, T. (1994). Locus coeruleus neurons in monkey are selectively activated by attended cues in a vigilance task. Journal of Neuroscience, 14, 4467-4480.

Botvinick, M. M., Braver, T. S., Barch, D. M., Carter, C. S., \& Cohen, J. C. (2001). Conflict monitoring and cognitive control. Psychological Review, 108, 624-652.

Botvinick, M. M., Cohen, J. D., \& Carter, C. S. (2004). Conflict monitoring and anterior cingulate cortex: An update. Trends in Cognitive Sciences, 8, 539-546.

Boucher, L., Logan, G. D., Palmeri, T. J., \& Schall, J. D. (2006). Modeling trial history of saccade countermanding (Online Program No. 48.8, Abstract Viewer and Itinerary Planner). Washington, DC: Society for Neuroscience Abstracts.

Boucher, L., Palmeri, T. J., Logan, G. D., \& Schall, J. D. (2007). Inhibitory control in mind and brain: An interactive race model of countermanding saccades. Psychological Review, 114, 376-397.

Braver, T. S., Barch, D. M., Gray, J. R., Molfese, D. L., \& Snyder, A. (2001). Anterior cingulate cortex and response conflict: Effects of frequency, inhibition and errors. Cerebral Cortex, 11, 825-836.

Brown, J. W., \& Braver, T. S. (2005). Learned predictions of error likelihood in the anterior cingulate cortex. Science, 307, 1118-1121.

Bruce, C. J., \& GoldBerg, M. E. (1985). Primate frontal eye fields: I. Single neurons discharging before saccades. Journal of Neurophysiology, 53, 603-635.

Bruce, C. J., Goldberg, M. E., Bushnell, C., \& Stanton, G. B. (1985). Primate frontal eye fields: II. Physiological and anatomical correlates of electrically evoked eye movements. Journal of Neurophysiology, 54, 714-734.

Bush, G., LUU, P., \& Posner, M. I. (2000). Cognitive and emotional influences in anterior cingulate cortex. Trends in Cognitive Sciences, 4, 215-222.

CARPENTER, R. H. S., \& Williams, M. L. L. (1995). Neural computation of $\log$ likelihood in the control of saccadic eye movements. Nature, 377, 59-62.

Cavina-Pratesi, C., Bricolo, E., Prior, M., \& Marzi, C. A. (2001). Redundancy gain in the stop-signal paradigm: Implications for the locus of coactivation in simple reaction time. Journal of Experimental Psychology: Human Perception \& Performance, 27, 932-941.

Chen, L. L., \& Wise, S. P. (1995). Neuronal activity in the supplementary eye field during acquisition of conditional oculomotor associations. Journal of Neurophysiology, 73, 1101-1121.

Curtis, C. E., Cole, M. W., Rao, V. Y., \& D'Esposito, M. (2005). Canceling planned action: An fMRI study of countermanding saccades. Cerebral Cortex, 15, 1281-1289.

Debener, S., Ullsperger, M., Siegel, M., Fiehler, K., von Cramon, D. Y., \& ENGEL, A. K. (2005). Trial-by-trial coupling of concurrent electroencephalogram and functional magnetic resonance imaging identifies the dynamics of performance monitoring. Journal of Neuroscience, 25, 11730-11737.

Dehaene, S., Posner, M. I., \& Tucker, D. M. (1994). Localization of a neural system for error detection and compensation. Psychological Science, 5, 303-305.

Dorris, M. C., \& Munoz, D. P. (1998). Saccadic probability influences motor preparation signals and time to saccadic initiation. Journal of Neuroscience, 18, 7015-7026.

Durstewitz, D. (2003). Self-organizing neural integrator predicts in- 
terval times through climbing activity. Journal of Neuroscience, 23, 5342-5353.

Emeric, E. E., Brown, J. W., Boucher, L., Carpenter, R. H. S., HANES, D. P., HARRIS, R., ET AL. (2007). Influence of history on countermanding performance in humans and macaque monkeys. Vision Research, 47, 35-49.

Everling, S., Dorris, M. C., Klein, R. M., \& Munoz, D. P. (1999). Role of primate superior colliculus in preparation and execution of anti-saccades and pro-saccades. Journal of Neuroscience, 19, 2740-2754.

Everling, S., \& MunOz, D. P. (2000). Neuronal correlates for preparatory set associated with pro-saccades and anti-saccades in the primate frontal eye field. Journal of Neuroscience, 20, 387-400.

Falkenstein, M., Hohnsbein, J., \& Hoormann, J. (1991). Effects of cross-modal divided attention on late ERP components: II. Error processing in choice reaction tasks. Electroencephalography \& Clinical Neurophysiology, 78, 447-455.

Falkenstein, M., Hohnsbein, J., \& Hoormann, J. (1995). Event related potential correlates of errors in reaction tasks. In G. Karmos, M. Molnár, V. Csépe, I. Czigler, \& J. E. Desmedt (Eds.), Perspectives of event-related potentials research (pp. 287-296). Amsterdam: Elsevier.

GandHI, N. J., \& Keller, E. L. (1999). Activity of the brain stem omnipause neurons during saccades perturbed by stimulation of the primate superior colliculus. Journal of Neurophysiology, 82, 3254-3267.

Garavan, H., Ross, T. J., Kaufman, J., \& Stein, E. A. (2003). A midline dissociation between error-processing and response-conflict monitoring. NeuroImage, 20, 1132-1139.

Gaymard, B., Ploner, C. J., Rivaud, S., Vermersch, A. I., \& PierrotDeseilligny, C. (1998). Cortical control of saccades. Experimental Brain Research, 123, 159-163.

Gehring, W. J., Goss, B., Coles, M. G. H., Meyer, D. E., \& DonCHIN, E. (1993). A neural system for error detection and compensation. Psychological Science, 4, 385-390.

Gratton, G., Coles, M. G. H., Sirevaag, E. J., Eriksen, C. W., \& Donchin, E. (1988). Pre- and poststimulus activation of response channels: A psychophysiological analysis. Journal of Experimental Psychology: Human Perception \& Performance, 14, 331-344.

Guitton, D., Bergeron, A., Choi, W. Y., \& Matsuo, S. (2003). On the feedback control of orienting gaze shifts made with eye and head movements. Progress in Brain Research, 142, 55-68.

Hanes, D. P., \& CARPEnTER, R. H. S. (1999). Countermanding saccades in humans. Vision Research, 39, 2777-2791.

Hanes, D. P., Patterson, W. F., II, \& Schall, J. D. (1998). The role of frontal eye fields in countermanding saccades: Visual, movement, and fixation activity. Journal of Neurophysiology, 79, 817-834.

Hanes, D. P., \& Schall, J. D. (1995). Countermanding saccades in macaque. Visual Neuroscience, 12, 929-937.

Hanes, D. P., \& Schall, J. D. (1996). Neural control of voluntary movement initiation. Science, 274, 427-430.

Holroyd, C. B., \& Coles, M. G. H. (2002). The neural basis of human error processing: Reinforcement learning, dopamine, and the errorrelated negativity. Psychological Review, 109, 679-709.

Holroyd, C. B., Yeung, N., Coles, M. G. H., \& Cohen, J. D. (2005). A mechanism for error detection in speeded response time tasks. Journal of Experimental Psychology: General, 134, 163-191.

Huerta, M. F., \& KaAs, J. H. (1990). Supplementary eye field as defined by intracortical microstimulation: Connections in macaques. Journal of Comparative Neurology, 293, 299-330.

Huerta, M. F., Krubitzer, L. A., \& KaAs, J. H. (1987). Frontal eye field as defined by intracortical microstimulation in squirrel monkeys, owl monkeys, and macaque monkeys: II. Cortical connections. Journal of Comparative Neurology, 265, 332-361.

Husain, M., Parton, A., Hodgson, T. L., Mort, D., \& Rees, G. (2003). Self-control during response conflict by human supplementary eye field. Nature Neuroscience, 6, 117-118.

Ito, S., Stuphorn, V., Brown, J. W., \& Schall, J. D. (2003). Performance monitoring by the anterior cingulate cortex during saccade countermanding. Science, 302, 120-122.

Johnston, K., Levin, H. M., Koval, M. J., \& Everling, S. (2007). Top-down control-signal dynamics in anterior cingulate and prefrontal cortex neurons following task switching. Neuron, 53, 453-462.

Jones, A. D., Cho, R. Y., Nystrom, L. E., Cohen, J. D., \& Braver, T. S. (2002). A computational model of anterior cingulate function in speeded response tasks: Effects of frequency, sequence, and conflict. Cognitive, Affective, \& Behavioral Neuroscience, 2, 300-317.

Kerns, J. G., Cohen, J. D., MacDonald, A. W., III, Cho, R. Y., Stenger, V. A., \& CARTer, C. S. (2004). Anterior cingulate conflict monitoring and adjustments in control. Science, 13, 1023-1026.

Kiehl, K. A., Liddle, P. F., \& Hopfinger, J. B. (2000). Error processing and the rostral anterior cingulate: An event-related fMRI study. Psychophysiology, 37, 216-223.

Lauwereyns, J., Watanabe, K., Coe, B., \& Hikosaka, O. (2002). A neural correlate of response bias in monkey caudate nucleus. Nature, 418, 413-417.

Lecas, J.-C., Requin, J., Anger, C., \& Vitton, N. (1986). Changes in neuronal activity of the monkey precentral cortex during preparation for movement. Journal of Neurophysiology, 56, 1680-1702.

Lo, C. C., \& WANG, X. J. (2006). Cortico-basal ganglia circuit mechanism for a decision threshold in reaction time tasks. Nature Neuroscience, 9, 956-963.

LogAN, G. D. (1994). On the ability to inhibit thought and action: A users' guide to the stop signal paradigm. In D. Dagenbach \& T. H. Carr (Eds.), Inhibitory processes in attention, memory, and language (pp. 189-239). San Diego: Academic Press.

Logan, G. D., \& CowAN, W. B. (1984). On the ability to inhibit thought and action: A theory of an act of control. Psychological Review, 91, 295-327.

Lu, X., Matsuzawa, M., \& Hikosaka, O. (2002). A neural correlate of oculomotor sequences in supplementary eye field. Neuron, 34, 317-325.

LuCE, R. D. (1986). Response times: Their role in inferring elementary mental organization. Oxford: Oxford University Press.

Luppino, G., Matelli, M., \& Rizzolatti, G. (1990). Cortico-cortical connections of two electrophysiologically identified arm representations in the mesial agranular frontal cortex. Experimental Brain Research, 82, 214-218.

Matsumoto, K., Matsumoto, M., Aвe, H., \& Tanaka, K. (2007). Medial prefrontal cell activity signaling prediction errors of action values. Nature Neuroscience, 10, 647-656.

Matsumoto, K., Suzuki, W., \& TanaKa, K. (2003). Neuronal correlates of goal-based motor selection in the prefrontal cortex. Science, 301, 229-232.

Miltner, W. H. R., Braun, C. H., \& Coles, M. G. H. (1997). Eventrelated brain potentials following incorrect feedback in a time-estimation task: Evidence for a "generic" neural system for error detection. Journal of Cognitive Neuroscience, 9, 787-797.

Mitz, A. R., \& Godschalk, M. (1989). Eye-movement representation in the frontal lobe of rhesus monkeys. Neuroscience Letters, 106, 157-162.

Munoz, D. P., \& IstVan, P. J. (1998). Lateral inhibitory interactions in the intermediate layers of the monkey superior colliculus. Journal of Neurophysiology, 79, 1193-1209.

Munoz, D. P., \& Wurtz, R. H. (1993). Fixation cells in monkey superior colliculus: II. Reversible activation and deactivation. Journal of Neurophysiology, 70, 576-589.

Murthy, A., Ray, S., Shorter, S. M., Priddy, E. G., Schall, J. D., \& Thompson, K. G. (2007). Frontal eye field contributions to rapid corrective saccades. Journal of Neurophysiology, 97, 1457-1469.

Murthy, A., Thompson, K. G., \& Schall, J. D. (2001). Dynamic dissociation of visual selection from saccade programming in FEF. Journal of Neurophysiology, 86, 2634-2637.

Mushiake, H., FujiI, N., \& TanjI, J. (1996). Visually guided saccade versus eye-hand reach: Contrasting neuronal activity in the cortical supplementary and frontal eye fields. Journal of Neurophysiology, 75, 2187-2191.

Nachev, P., Rees, G., Parton, A., Kennard, C., \& Husain, M. (2005). Volition and conflict in human medial frontal cortex. Current Biology, 15, 122-128.

Nakamura, K., Roesch, M. R., \& Olson, C. R. (2005). Neuronal activity in macaque SEF and ACC during performance of tasks involving conflict. Journal of Neurophysiology, 93, 884-908.

Niki, H., \& Watanabe, M. (1976). Cingulate unit activity and delayed response. Brain Research, 110, 381-386.

Niki, H., \& Watanabe, M. (1979). Prefrontal and cingulate unit activity during timing behavior in the monkey. Brain Research, 171, 213-224. 
Olson, C. R., \& Gettner, S. N. (1999). Macaque SEF neurons encode object-centered directions of eye movements regardless of the visual attributes of instructional cues. Journal of Neurophysiology, 81, 2340-2346.

O’Sullivan, E. P., Jenkins, I. H., Henderson, L., Kennard, C., \& Brooks, D. J. (1995). The functional anatomy of remembered saccades: A PET study. NeuroReport, 6, 2141-2144.

Paré, M., \& Hanes, D. P. (2003). Controlled movement processing: Superior colliculus activity associated with countermanded saccades. Journal of Neuroscience, 23, 6480-6489.

Parthasarathy, H. B., Schall, J. D., \& Graybiel, A. M. (1992) Distributed but convergent ordering of corticostriatal projections: Analysis of the frontal eye field and the supplementary eye field in the macaque monkey. Journal of Neuroscience, 12, 4468-4488.

Parton, A., Nachev, P., Hodgson, T. L., Mort, D., Thomas, D., OrDIDGE, R., ET AL. (2007). Role of the human supplementary eye field in the control of saccadic eye movements. Neuropsychologia, $\mathbf{4 5}$, 997-1008.

Paus, T., Petrides, M., Evans, A. C., \& Meyer, E. (1993). Role of the human anterior cingulate cortex in the control of oculomotor, manual, and speech responses: A positron emission tomography study. Journal of Neurophysiology, 70, 453-469.

Paus, T., Tomaiuolo, F., Otaky, N., MacDonald, D., Petrides, M., Atlas, J., ET AL. (1996). Human cingulate and paracingulate sulci: Pattern, variability, asymmetry, and probabilistic map. Cerebral Cortex, 6, 207-214

Petit, L., Courtney, S. M., Ungerleider, L. G., \& Haxby, J. V. (1998). Sustained activity in the medial wall during working memory delays. Journal of Neuroscience, 18, 9429-9437.

Petit, L., Orssaud, C., Tzourio, N., Salamon, G., Mazoyer, B., \& BERTHOZ, A. (1993). PET study of voluntary saccadic eye movements in humans: Basal ganglia-thalamocortical system and cingulate cortex involvement. Journal of Neurophysiology, 69, 1009-1017.

ProcyK, E., TanaKa, Y. L., \& JosePh, J. P. (2000). Anterior cingulate activity during routine and non-routine sequential behaviors in macaques. Nature Neuroscience, 3, 502-508.

RabBITT, P. M. A. (1966). Errors and error-correction in choice-response tasks. Journal of Experimental Psychology, 71, 264-272.

RATCLIFF, R., \& SMith, P. L. (2004). A comparison of sequential sampling models for two-choice reaction time. Psychological Review, 111, 333-367.

Ridderinkhof, K. R., Ullsperger, M., Crone, E. A., \& NieuwenHUIS, S. (2004). The role of the medial frontal cortex in cognitive control. Science, 306, 443-447.

RIEGER, M., \& GAUGGEL, S. (1999). Inhibitory after-effects in the stop signal paradigm. British Journal of Psychology, 90, 509-518.

Roelofs, A., van Turennout, M., \& Coles, M. G. H. (2006). Anterior cingulate cortex activity can be independent of response conflict in Stroop-like tasks. Proceedings of the National Academy of Sciences, 103, 13884-13889.

Sato, T. R., \& Schall, J. D. (2003). Effects of stimulus-response compatibility on neural selection in frontal eye field. Neuron, 38, 637-648.

SCHALL, J. D. (1991a). Neuronal activity related to visually guided saccades in the frontal eye fields of rhesus monkeys: Comparison with supplementary eye fields. Journal of Neurophysiology, 66, 559-579.

ScHALL, J. D. (1991b). Neuronal activity related to visually guided saccadic eye movements in the supplementary motor area of rhesus monkeys. Journal of Neurophysiology, 66, 530-558.

SCHALL, J. D. (1997). Visuomotor areas of the frontal lobe. In K. Rockland, A. Peters, \& J. Kaas (Eds.), Cerebral cortex: Vol. 12. Extrastriate cortex of primates (pp. 527-638). New York: Plenum.

SCHALL, J. D. (2004). On building a bridge between brain and behavior Annual Review of Psychology, 55, 23-50.

Schall, J. D., Stuphorn, V., \& Brown, J. W. (2002). Monitoring and control of action by the frontal lobes. Neuron, 36, 309-322.

Schall, J. D., \& Thompson, K. G. (1999). Neural selection and control of visually guided eye movements. Annual Review of Neuroscience, 22, 241-259

Scheffers, M. K., Coles, M. G. H., Bernstein, P., Gehring, W. J., \& Donchin, E. (1996). Event-related brain potentials and error-related processing: An analysis of incorrect responses to go and no-go stimuli. Psychophysiology, 33, 42-53.

SCHILlER, P. H., \& CHOU, I. (2000). The effects of anterior arcuate and dorsomedial frontal cortex lesions on visually guided eye movements in the rhesus monkey: 1. Single and sequential targets. Vision Research, 40, 1609-1626.

Schiller, P. H., True, S. D., \& Conway, J. D. (1980). Deficits in eye movements following frontal eye field and superior colliculus ablations. Journal of Neurophysiology, 44, 1175-1189.

Schlag, J., \& Schlag-Rey, M. (1987). Evidence for a supplementary eye field. Journal of Neurophysiology, 57, 179-200.

Schlag-Rey, M., Amador, N., Sanchez, H., \& Schlag, J. (1997). Antisaccade performance predicted by neuronal activity in the supplementary eye field. Nature, 390, 398-401.

Schultz, W. (2007). Multiple dopamine functions at different time courses. Annual Review of Neuroscience, 30, 259-288.

SEgRAVES, M. A. (1992). Activity of monkey frontal eye field neurons projecting to oculomotor regions of the pons. Journal of Neurophysiology, 68, 1967-1985.

Segraves, M. A., \& Goldberg, M. E. (1987). Functional properties of corticotectal neurons in the monkey's frontal eye field. Journal of Neurophysiology, 58, 1387-1419.

Shidara, M., \& Richmond, B. J. (2002). Anterior cingulate: Single neuronal signals related to degree of reward expectancy. Science, 296, 1709-1711.

Shima, K., Aya, K., Mushiake, H., Inase, M., Aizawa, H., \& Tanji, J. (1991). Two movement-related foci in the primate cingulate cortex observed in signal-triggered and self-paced forelimb movements. Journal of Neurophysiology, 65, 188-202.

SHIMA, K., \& TANJI, J. (1998). Role of cingulate motor area cells in voluntary movement selection based on reward. Science, 282, 1335-1338.

Sommer, M. A., \& Wurtz, R. H. (2000). Composition and topographic organization of signals sent from the frontal eye field to the superior colliculus. Journal of Neurophysiology, 83, 1979-2001.

SparKs, D. L. (2002). The brainstem control of saccadic eye movements. Nature Reviews Neuroscience, 3, 952-964.

Stanton, G. B., Bruce, C. J., \& Goldberg, M. E. (1993). Topography of projections to the frontal lobe from the macaque frontal eye fields. Journal of Comparative Neurology, 330, 286-301.

Stuphorn, V., \& Schall, J. D. (2006). Executive control of countermanding saccades by the supplementary eye field. Nature Neuroscience, 9, 925-931

Stuphorn, V., Taylor, T. L., \& Schall, J. D. (2000). Performance monitoring by the supplementary eye field. Nature, 408, 857-860.

Sumner, P., Nachev, P., Morris, P., Peters, A. M., Jackson, S. R., Kennard, C., \& HusaIn, M. (2007). Human medial frontal cortex mediates unconscious inhibition of voluntary action. Neuron, 54, 697-711.

Takahashi, M., Sugiuchi, Y., Izawa, Y., \& Shinoda, Y. (2005). Synaptic inputs and their pathways from fixation and saccade zones of the superior colliculus to inhibitory burst neurons and pause neurons. In S. Ramat \& D. Straumann (Eds.), Clinical and basic oculomotor research (Annals of the New York Academy of Sciences, Vol. 1039, pp. 209-219). New York: New York Academy of Sciences.

Taylor, S. F., Martis, B., Fitzgerald, K. D., Welsh, R. C., Abelson, J. L., LIBERZON, I., ET AL. (2006). Medial frontal cortex activity and lossrelated responses to errors. Journal of Neuroscience, 26, 4063-4070.

Ullsperger, M., \& vON Cramon, D. Y. (2001). Subprocesses of performance monitoring: A dissociation of error processing and response competition revealed by event-related fMRI and ERPs. NeuroImage, 14, 1387-1401

Usher, M., \& McClelland, J. L. (2001). The time course of perceptual choice: The leaky, competing accumulator model. Psychological Review, 108, 550-592.

Verbruggen, F., Liefooghe, B., \& Vandierendonck, A. (2005). On the difference between response inhibition and negative priming: Evidence from simple and selective stopping. Psychological Research, 69, 262-271.

Yeung, N., Botvinick, M. M., \& Cohen, J. D. (2004). The neural basis of error detection: Conflict monitoring and the error-related negativity. Psychological Review, 111, 931-959.

Yeung, N., Holroyd, C. B., \& Cohen, J. D. (2005). ERP correlates of feedback and reward processing in the presence and absence of response choice. Cerebral Cortex, 15, 535-544.

(Manuscript received March 6, 2007; revision accepted for publication August 15, 2007.) 